\title{
pH Regulation of Ammonia Secretion by Colletotrichum gloeosporioides and Its Effect on Appressorium Formation and Pathogenicity
}

\author{
Itay Miyara, ${ }^{1,3}$ Hadas Shafran, ${ }^{2}$ Maayan Davidzon, ${ }^{1}$ Amir Sherman, ${ }^{2}$ and Dov Prusky ${ }^{1}$ \\ ${ }^{1}$ Department of Postharvest Science of Fresh Produce and ${ }^{2}$ Department of Genomics, Agricultural Research Organization, \\ the Volcani Center, Bet Dagan 50250; ${ }^{3}$ The Hebrew University of Jerusalem, The Robert H. Smith Faculty of Agriculture, \\ Food and Environment, Rehovot 76100, Israel
}

Submitted 27 July 2009. Accepted 22 October 2009.

\begin{abstract}
Host-tissue alkalinization via ammonia accumulation is key to Colletotrichum spp. colonization. Using macroarrays carrying $C$. gloeosporioides cDNAs, we monitored gene expression during the alkalinization process. A set of genes involved in synthesis and catabolism of ammonia accumulation were identified. Expression of $\mathrm{NAD}^{+}$-specific glutamate dehydrogenase ( $G D H 2$, encoding ammonia synthesis) and the ammonia exporter $A M E T$ were induced at $\mathrm{pH} 4.0$ to 4.5. Conversely, ammonia uptake and transcript activation of the ammonia and glutamate importers (MEP and $G L T$, respectively) and glutamine synthase (GS1) were higher at pH 6.0 to 7.0. Accumulated ammonia in the wildtype mycelium decreased during ambient alkalinization, concurrent with increased $G S 1$ expression. $\Delta$ pac1 mutants of $C$. gloeosporioides, which are sensitive to alkaline pH changes, showed upregulation of the acid-expressed $G \mathrm{DH} 2$ and downregulation of the alkaline-expressed $G S 1$, resulting in $60 \%$ higher ammonia accumulation inside the mycelium. $\Delta g d h 2$ strains of $C$. gloeosporioides, impaired in ammonia production, showed $85 \%$ inhibition in appressorium formation followed by reduced colonization on avocado fruit (Persea americana cv. Fuerte) pericarp, while exogenic ammonia addition restored appressoria formation. Thus the modulation of genes involved in ammonia metabolism and catabolism by $C$. gloeosporioides is ambient $\mathbf{p H}$-dependent. Aside from its contribution to necrotrophic stages, ammonia accumulation by germinating spores regulates appressorium formation and determines the initiation of biotrophic stages of avocado-fruit colonization by Colletotrichum spp.
\end{abstract}

Colletotrichum gloeosporioides (Penz.) Penz. \& Sacc. is a broad-host range plant-pathogenic fungus that alkalinizes hosttissue $\mathrm{pH}$ during disease development (Prusky et al. 2001). Host alkalinization involves the active secretion of ammonia induced by relatively low host $\mathrm{pH}$, as detected in several Colletotrichuminfected fruits (Alkan et al. 2008; Diéguez-Uribeondo et al.

Corresponding author: D. Prusky; Telephone: +972 3 9693880; Fax: +972 3 9683622; E-mail: dovprusk@agri.gov.il

* The $\boldsymbol{e}$-Xtra logo stands for "electronic extra" and indicates that Figure 8 appears in color online.

This article is in the public domain and not copyrightable. It may be freely reprinted with customary crediting of the source. The American Phytopathological Society, 2010.
2008; Drori et al. 2003; Prusky and Yakoby 2003). For instance, the $\mathrm{pH}$ of avocado mesocarp was found to increase from 5.6 in healthy fruit to 8.5 in C. gloeosporioides-colonized fruit, while ammonia accumulation increased by almost 500\% (Prusky et al. 2001; Yakoby et al. 2000). Alkalinization of the host tissue by ammonia ensures that specific pathogenicity factors, such as $P E L B$ encoding for pectate lyase, are expressed by the pathogen under the environmental conditions in which they are most effective (Drori et al. 2003; Eshel et al. 2002; KramerHaimovich et al. 2006; Yakoby et al. 2000). Colletotrichum strains with reduced ammonia secretion, such as the $\mathrm{Nit}^{-}$and $\triangle$ are $^{-}$mutants, show a significant reduction in pathogenicity (Alkan et al. 2008), a finding consistent with the involvement of ammonia accumulation during fungal colonization.

To achieve a more accurate analysis of $C$. gloeosporioides genes regulated by the alkalinization process, we constructed a cDNA macroarray and identified genes that displayed up- and downregulation under conditions regulating ammonia induction. One of the key genes catalyzing ammonia accumulation during the early alkalinization process is glutamate dehydrogease $(G D H 2)$. Our analysis showed that the modulation of ammonia accumulation in germinating spores triggers appressorium formation and suggested the importance of ammonia as a pathogenicity determinant in Colletotrichum spp. We concluded that differential gene expression during C. gloeosporioides development, accompanied by ammonia production and host alkalinization, is required for proper differentiation at initial stages of spore germination and penetration as well as for the transition from quiescent-biotrophic to active-necrotrophic interactions that determine the extent of host colonization by C. gloeosporioides.

\section{RESULTS}

Establishment of the macroarray and comparative hybridization during alkalinization conditions.

A cDNA library of the fungus was created in conditions that mimicked the $\mathrm{pH}$ conditions of the pathogenic stage of C. gloeosporioide infection (Drori et al. 2003). The fungus was grown for 3 days in primary medium and then transferred for $24 \mathrm{~h}$ to a secondary medium (SM) buffered with phthalate buffer to an initial $\mathrm{pH}$ of 6.0. The SM contained $1 \%$ avocado cell wall as a carbon source and $50 \mathrm{mM}$ L-glutamine as a nitrogen source. A second cDNA library that represented the growth stage of $C$. gloeosporioides on avocado mesocarp was generated from hyphae growing on avocado fruits (discussed below). An increase in $\mathrm{pH}$ from 5.7 to 7.5 was observed in the avocado tissue as a 
result of the fungal colonization. To assess the complexity of these libraries, 210 clones were sequenced; most of the cDNAs were unique. Therefore, we assumed that these libraries provide a good representation of the RNAs that are expressed under alkalinization conditions. However, the cDNA of one clone, the CAP5 (U18757), appeared in a much higher frequency (5.7\% of all the clones). A macroarray was constructed from these cDNA libraries by spotting two replicates of 9,984 unknown colonies containing cDNA fragments onto nylon membranes.

To determine the expression of specific genes expressed during the alkalinization process, the array was hybridized with labeled cDNAs from Colletotrichum mycelia growing under various $\mathrm{pH}$ conditions. The hybridization signal of the array was quantified by comparing the hybridized signals from fungi grown at a low $\mathrm{pH}$ of 4.0 to 4.5 and a high $\mathrm{pH}$ of 6.0 to 7.0 on the same spot of the array. Clones that showed differential expression were sequenced. We estimate that $2.5 \%$ of the expressed sequence tags (EST) were expressed differentially (50 out of a total of 2,000 visible spots on the macroarray). Sequences were deposited in GenBank and assigned the accession numbers GH270292 to GH270326. Among the identified genes were eight genes related to nitrogen and ammonia metabolism, seven genes related to carbon metabolism, two genes related to calcium signaling, the glycosyl hydrolase DFG5 gene (defective for filamentous growth), which is a sensor for alkaline $\mathrm{pH}$ damage in yeast (Spreghini et al. 2003), and others (Table 1). In an independent biological experiment, the expression of 10 genes was determined by real-time quantitative polymerase chain reaction (qPCR) (Table 2). The findings were generally consistent with the macroarray data.

Previous findings regarding the importance of ammonia accumulation in the modulation of pathogenicity (Alkan et al. 2008) and the differential expression observed for genes associated with ammonia metabolism led us to focus on genes related to ammonia regulation, i.e., $\mathrm{NAD}^{+}$-specific glutamate dehydrogenase $(G D H 2)$, ammonia exporter $(A M E T)$ and importers $(M E P, M E P B)$, glutamate-like transporter $(G L T)$, and glutamine

Table 1. Gene annotation and expression profile of Colletotrichum gloeosporioides wild-type strain ${ }^{\mathrm{a}}$

\begin{tabular}{|c|c|c|c|c|c|c|}
\hline \multirow[b]{2}{*}{ GenBank no. } & \multirow[b]{2}{*}{ Putative homolog ${ }^{b}$} & \multirow[b]{2}{*}{ Gene name $^{\mathrm{c}}$} & \multirow[b]{2}{*}{ E value $^{d}$} & \multicolumn{2}{|c|}{ Spot density ${ }^{\mathrm{e}}$} & \multirow[b]{2}{*}{ Fold change $^{f}$} \\
\hline & & & & pH 4.0 to 4.5 & pH 6.0 to 7.0 & \\
\hline \multicolumn{7}{|c|}{ Nitrogen metabolism } \\
\hline GH270292 & H.P.-like NAD ${ }^{+}$dep. glt dehydrogenase & $G D H 2$ & 5e-166 (XM_951687) & $7.8 \pm 2.3$ & $1.0 \pm 0.7$ & 0.12 \\
\hline GH270293 & H.P. amidohydrolase family protein & AMHS & 9e-67 (XM_001824914) & $2.2 \pm 0.2$ & $0.3 \pm 0.0$ & 0.13 \\
\hline GH270294 & H.P.-like glutamate transporter & $G L T$ & 4e-61 (XM_001225097) & $0.2 \pm 0.0$ & $0.6 \pm 0.0$ & 3 \\
\hline GH270295 & Glutamine synthetase & GSI & $6 \mathrm{e}-93(\mathrm{~L} 78067)$ & $3.9 \pm 1.3$ & $13.3 \pm 0.1$ & 3.33 \\
\hline GH270296 & Nitrogen starvation-induced & NSIB & 2e-117 (U94184) & $4.7 \pm 5.1$ & $20.3 \pm 2.9$ & 4.31 \\
\hline GH270297 & H.P. GPR1/FUN34/yaaH family & AMET & 8e-22 (XP_001226124) & $0.3 \pm 0.0$ & $1.5 \pm 0.8$ & 4.66 \\
\hline GH270298 & Nitrogen starvation-induced glutamine rich protein & NSIA & $7 \mathrm{e}-65$ (U94186) & $0.3 \pm 0.0$ & $2.9 \pm 0.4$ & 9.66 \\
\hline GH270299 & Ammonium transporter & $M E P$ & 0.77 (AAY35262) & $0.6 \pm 0.0$ & $5.5 \pm 0.0$ & 9.16 \\
\hline \multicolumn{7}{|c|}{ Carbon metabolism } \\
\hline GH270300 & Succinate semialdehyde dehydrogenase & $S S D$ & 3e-33 (XM_001266487) & $4.5 \pm 0.6$ & $0.5 \pm 0.6$ & 0.11 \\
\hline GH270301 & H.P.-like monosaccharide transporter & MSTA & 1e-87 (XM_001227939) & $10.7 \pm 0.0$ & $2.1 \pm 1.3$ & 0.19 \\
\hline $\mathrm{GH} 270302$ & H.P.-like hexose transporter & $H X T 2$ & 2e-46 (XM_001228227) & $3.4 \pm 0.3$ & $1.1 \pm 0$ & 0.32 \\
\hline GH270303 & Phosphoenolpyruvate carboxykinase & PEPCK & 2e-150 (XM_368794) & $2.0 \pm 0.6$ & $6.3 \pm 0.6$ & 3.15 \\
\hline $\mathrm{GH} 270304$ & H.P.-like citrate synthase & & 2e-162 (XM_380351) & $0.1 \pm 0.0$ & $0.4 \pm 0.0$ & 4 \\
\hline GH270305 & Indole-3-pyruvate decarboxylase & & $5 \mathrm{e}-103$ ( EU304327) & $0.7 \pm 0.4$ & $4.4 \pm 0.3$ & 6.28 \\
\hline GH270306 & H.P.-like glucose-repressible protein & GRG1 & 2e-27 (XM_677462) & $0.3 \pm 0.2$ & $5.1 \pm 0.0$ & 17 \\
\hline \multicolumn{7}{|c|}{ Calcium signaling } \\
\hline GH270307 & H.P.-like calcipressin & $C A L$ & 7e-33 (XM_381626) & $0.5 \pm 0.3$ & $1.7 \pm 0.3$ & 3.4 \\
\hline $\mathrm{GH} 270308$ & H.P.-like $\mathrm{Ca}^{2+}$-binding protein & $C D C 4$ & 1e-87 (XM_364625) & $0.3 \pm 0.0$ & $1.6 \pm 0.4$ & 5.33 \\
\hline \multicolumn{7}{|l|}{ Other } \\
\hline GH270309 & H.P. & & 5e-04 (XM_001223827) & $20.8 \pm 0.9$ & $1.6 \pm 0.0$ & 0.08 \\
\hline $\mathrm{GH} 270310$ & H.P. & & 6e-05 (XM_957189) & $13.9 \pm 0.2$ & $1.4 \pm 0.3$ & 0.1 \\
\hline GH270311 & H.P. & & 4e-68 (XM_959690) & $4.5 \pm 0.5$ & $0.5 \pm 0.0$ & 0.12 \\
\hline $\mathrm{GH} 270312$ & H.P. & & 4e-18 (XM_388089) & $2.8 \pm 1.6$ & $0.5 . \pm 0.1$ & 0.19 \\
\hline $\mathrm{GH} 270313$ & H.P.-like NAD ${ }^{+}$epimerase/dehydratase family & $E P M E$ & 1e-77 (XM_389870) & $5.2 \pm 0.5$ & $1.0 \pm 0.0$ & 0.19 \\
\hline $\mathrm{GH} 270314$ & 3-ketoacyl-CoA thiolase & & 2e-82 (XM_955329) & $4.8 \pm 0.3$ & $1.1 \pm 0.4$ & 0.22 \\
\hline $\mathrm{GH} 270315$ & H.P.-like copper resistance protein & & 8e-25 (XM_388348) & $8.4 \pm 0.5$ & $1.8 \pm 0.6$ & 0.22 \\
\hline GH270316 & H.P.-like NADH-cytochrome b5 reductase & & 2e-82 (XM_001545681) & $3.8 \pm 0.1$ & $0.9 \pm 0.2$ & 0.24 \\
\hline $\mathrm{GH} 270317$ & H.P. & & 8e-35 (XM_387006) & $6.7 \pm 1.4$ & 1.6. \pm 03 & 0.24 \\
\hline $\mathrm{GH} 270318$ & $60 \mathrm{~S}$ acidic ribosomal P1 & & $1 \mathrm{e}-23(\mathrm{X} 84216)$ & $3.7 \pm 0.2$ & $0.9 \pm 0.0$ & 0.24 \\
\hline GH270319 & H.P.-like polyketide synthase & & 2e-26(XM_364800) & $1.9 \pm 0.8$ & $0.6 \pm 0.2$ & 0.32 \\
\hline $\mathrm{GH} 270320$ & H.P. & & 4e-04 (XM_381731) & $1.9 \pm 1.5$ & $6.7 \pm 3.8$ & 3.41 \\
\hline GH270326 & Cell-wall glycosyl hydrolase & $D F G 5$ & 7e-15 (XM_956160) & $0.2 \pm 0.0$ & $0.8 \pm 0.0$ & 4 \\
\hline GH270321 & Short-chain dehydrogenase/reductase family & & 1e-65(XM_741422) & $0.2 \pm 0.0$ & $1.01 \pm 0.4$ & 5.05 \\
\hline $\mathrm{GH} 270322$ & H.P. cyanovirin-N family & & 8e-36(XM_744886) & $0.5 \pm 0.6$ & $3.6 \pm 0.2$ & 7.05 \\
\hline GH270323 & H.P. & $H P I$ & 2e-08 (XM_001224488) & $3.2 \pm 0.2$ & $0.9 \pm 0.8$ & 12.51 \\
\hline $\mathrm{GH} 270324$ & H.P. & & 1e-04 (XM_381199) & $1.2 \pm 0.4$ & $20.9 \pm 4.6$ & 16.5 \\
\hline $\mathrm{GH} 270325$ & H.P. & & 5e-16 (XM_001405682) & $0.2 \pm 0.0$ & $4.4 \pm 0.2$ & 19.2 \\
\hline
\end{tabular}

a The fungus was grown for 3 days in primary medium and then transferred to secondary medium amended with avocado cell wall and glutamate and grown at $\mathrm{pH} 4.0$ to 4.5 or 6.0 to 7.0 for $24 \mathrm{~h}$.

${ }^{\mathrm{b}}$ H.P. = hypothetical protein.

c The gene name is based on homology to databases.

${ }^{d}$ Best fit in GenBank is shown as excision number. The $\mathrm{E}$ value is related to the presented excision number.

e Gene expression levels are presented as density of the individual spot as detected. One experiment including the average of two replications \pm standard deviation is presented.

${ }^{\mathrm{f}}$ Fold change was calculated by dividing the expression level at $\mathrm{pH} 6.0$ to 7.0 by that at $\mathrm{pH} 4.0$ to 4.5 . 
synthase (GS1). $M E P B$ is an ammonium transporter ortholog that was cloned independently of the array, as described below.

\section{Genes involved in ammonia production and secretion by $C$. gloeosporioides.}

The effect of $G D H 2$ expression on ammonia accumulation was observed as a function of $\mathrm{pH}$, nitrogen source, and glutamate concentration. Growth of $C$. gloeosporioides on SM amended with $50 \mathrm{mM}$ L-glutamate at $\mathrm{pH} 4.0$ showed a 2.0 - to 5.0-fold increase in ammonia accumulation (Fig. 1A) and an 80-fold increase in $G D H 2$ expression (Fig. 1B) during the first $12 \mathrm{~h}$ after inoculation compared with the levels detected at $\mathrm{pH}$ 6.0. Amendment of SM with $50 \mathrm{mM} \mathrm{L}$-glutamate or an equivalent nitrogen concentration of glutamine also affected $G D H 2$ expression at $\mathrm{pH}$ 5.0. After $24 \mathrm{~h}$ of fungal growth in SM, the highest concentration of ammonia accumulated $(15.5 \mathrm{mM})$ and the highest $G D H 2$ expression (10 times that with no nitrogen source) were observed in the medium amended with L-glutamate.

Ammonia secretion in yeast is modulated by the Yaah family Ato protein (Ricicova et al. 2007). The activation level of the AMET gene, a C. gloeosporioides homolog of Saccharomyces cerevisiae Ato $2 \mathrm{p}$, is also dependent on $\mathrm{pH}$, as shown in the array results (Table 2). An increase in L-glutamate concentration from 0 to $50 \mathrm{mM}$ yielded a 6.8 -fold increase in ammonia accumulation and 24.5- and 35-fold increases in the relative expressions of $G D H 2$ and $A M E T$, respectively (Fig. 2), indicating the coordinated activation of both genes for the production and export of ammonia.

\section{Genes involved in ammonia uptake and metabolism by $C$. gloeosporioides.}

The relative expressions of $C$. gloeosporioides $M E P$ in the array (Table 1) and of $M E P B$ in an independent experiment (data not shown) at $\mathrm{pH} 6.0$ to $7.0,24 \mathrm{~h}$ after inoculation were nine and 12 times higher, respectively, than at $\mathrm{pH} 4.0$ to 4.5 . To determine the involvement of $M E P B$ in the uptake of ammonia, experiments involving the export followed by import of ammonia were carried out (Fig. 3). Inoculation of fungi into medium amended with $10 \mathrm{mM}$ L-glutamate at $\mathrm{pH} 4.0$ resulted in accumulation of ammonia to as high as $15.5 \mathrm{mM}$ and a $\mathrm{pH}$ increase of 2.6 units after $18 \mathrm{~h}$ (Fig. 3A). The hyphal mat was then washed again and transferred to SM amended with 10 $\mathrm{mM} \mathrm{NH} \mathrm{Cl}_{4}$ (ammonia-consuming medium) at an initial $\mathrm{pH}$ of 6.5 ; in this case, uptake of ammonia reduced its concentration in the medium to $8 \mathrm{mM}$ and the $\mathrm{pH}$ by $1.8 \mathrm{pH}$ units. Whereas the secretion of ammonia was accompanied by a 100-fold decrease in $M E P B$ expression, the uptake of ammonia resulted in a rapid increase in relative expression of $M E P B$ by 80 -fold after $18 \mathrm{~h}$ (Fig. 3B). In parallel to the expression of $M E P B$, a glutamate transporter $G L T$ was also strongly induced by alkaline $\mathrm{pH} 6.5$ (Tables 1 and 2), suggesting that ammonia accumulation is dependent on the import of the glutamate required for $G D H 2$ activation.
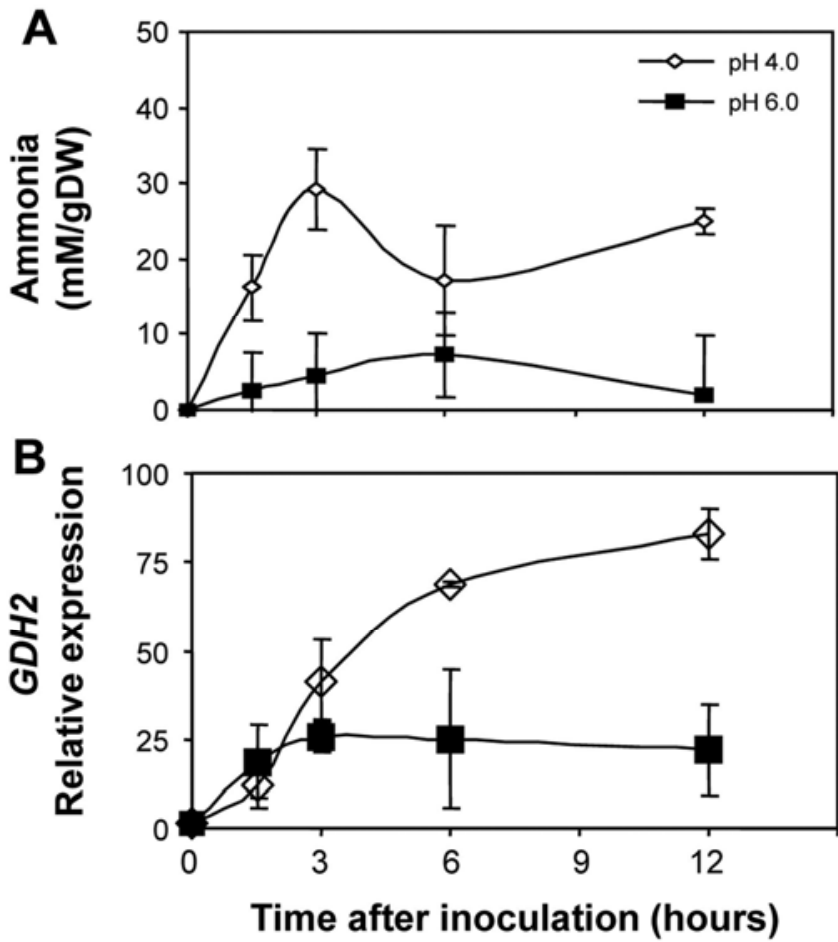

Fig. 1. Effect of $\mathrm{pH}$ on ammonia accumulation and relative $G D H 2$ expression by Colletotrichum gloeosporioides. A, Accumulation of ammonia in secondary medium (SM) media. B, Relative expression of $G D H 2$ as determined by comparison with the $18 \mathrm{~S}$ ribosomal gene, detected by quantitative polymerase chain reaction analysis of total RNA isolated from $C$. gloeosporioides mycelia. Media and mycelia were sampled at different intervals after transfer of mycelia from the primary medium to SM amended with L-glutamate and buffered with phthalate buffer to an initial $\mathrm{pH}$ of 4.0 or 6.0. Averages of three replications \pm standard deviation are presented.

Table 2. Real-time quantitative polymerase chain reaction (qPCR) analysis of selected expressed sequence tags for macroarray validation ${ }^{\mathrm{a}}$

\begin{tabular}{|c|c|c|c|c|c|c|}
\hline \multirow[b]{2}{*}{ Gene $^{\text {b }}$} & \multicolumn{3}{|c|}{$12 \mathrm{~h}$} & \multicolumn{3}{|c|}{$24 \mathrm{~h}$} \\
\hline & pH 4.0 to 4.5 & $\mathrm{pH} 6.0$ to 7.0 & Fold change & pH 4.0 to 4.5 & pH 6.0 to 7.0 & Fold change ${ }^{c}$ \\
\hline$S S D$ & $0.91 \pm 0.1$ & $0.33 \pm 0.1$ & 0.36 & $0.67 \pm 0.0$ & $0.01 \pm 0.0$ & 0.01 \\
\hline$E P M E$ & $0.77 \pm 0.3$ & $0.14 \pm 0.0$ & 0.18 & $0.63 \pm 0.3$ & $0.08 \pm 0.0$ & 0.12 \\
\hline AMHS & $1.08 \pm 0.1$ & $0.18 \pm 0.1$ & 0.16 & $0.87 \pm 0.6$ & $0.24 \pm 0.1$ & 0.27 \\
\hline GSI & $0.60 \pm 0.0$ & $2.61 \pm 0.5$ & 4.35 & $3.10 \pm 0.1$ & $14.0 \pm 0.7$ & 4.53 \\
\hline AMET & $9.30 \pm 0.1$ & $2.20 \pm 0.7$ & 0.24 & $0.2 \pm 0.0$ & $2.4 \pm 0.9$ & 8.96 \\
\hline NSIA & $1.16 \pm 0.2$ & $1.02 \pm 0.0$ & 0.87 & $0.40 \pm 0.1$ & $6.09 \pm 0.0$ & 15.20 \\
\hline PEPCK & $1.06 \pm 0.0$ & $0.54 \pm 0.0$ & 0.5 & $0.16 \pm 0.0$ & $2.54 \pm 0.89$ & 15.80 \\
\hline$G L T$ & $0.21 \pm 0.0$ & $37.2 \pm 3.6$ & 177.1 & $3.27 \pm 0.1$ & $62.5 \pm 4.2$ & 19.10 \\
\hline$H P I$ & $0.98 \pm 0.0$ & $23.6 \pm 6.2$ & 24.0 & $0.16 \pm 0.0$ & $8.2 \pm 1.4$ & 51.10 \\
\hline DFG5 & $0.83 \pm 0.2$ & $46.9 \pm 5.5$ & 56.5 & $0.10 \pm 0.0$ & $412.6 \pm 28$ & 4,126 \\
\hline
\end{tabular}

${ }^{a}$ Gene expression, by qPCR, in the wild-type strain cultured for 3 days in primary medium and then transferred to the secondary medium amended with 50 $\mathrm{mM}$ glutamate and grown at $\mathrm{pH} 4.0$ to 4.5 or 6.0 to 7.0 for another 12 and $24 \mathrm{~h}$

${ }^{\mathrm{b}} S S D=$ succinate semialdehyde dehydrogenase homologous; $E P M E=$ H.P.-like NAD ${ }^{+}$epimerase/dehydratase family; $A M H S=$ H.P.-like amidohydrolase family protein; $G S 1$ = glutamine synthetase; $A M E T=$ H.P.-like GPR1/FUN34/yaaH family (ammonia exporter); NSIA = nitrogen starvation-induced glutamine-rich protein; $P E P C K=$ phosphoenolpyruvate carboxykinase homologous; $G L T=$ H.P.-like glutamate transporter; $H P 1=$ hypothetical protein, XM_001224488 homologous; DFG5 = cell-wall glycosyl hydrolase homologous.

${ }^{\mathrm{c}}$ For qPCR, fold change values are relative to the expression at $\mathrm{pH} 4.0$ to 4.5 compared with the expression at $\mathrm{pH} 6.0$ to 7.0 at each sampling time (12 and $24 \mathrm{~h}$ ) and normalized by $18 \mathrm{~S}$ ribosomal gene. Relative expression was detected at least three independent times and found consistent. The average of two replications \pm standard deviation of one experiment is presented. 
Relative expression of GS1 is an important factor in determining the fate of the assimilated ammonia, and its residual concentrations in the medium and in the hyphae. Relative expression of $G S 1$ when the fungus was grown in SM amended with $10 \mathrm{mM}$ ammonia at $\mathrm{pH} 6.5$ was up-regulated 12-fold compared with growth under similar conditions but at $\mathrm{pH} 3.5$ (Fig. 4A). Expression of GS1 was inversely related to the residual ammonia concentrations inside the hyphae and in the growth medium (Fig. 4B), suggesting that ammonia metabolism by GS1 increased with increasing $\mathrm{pH}$. These findings demonstrate that GS1 is an early fungal response gene that may modulate the initial stages of pathogen development by controlling the exported ammonia levels.

Effect of $\mathrm{pH}$ on the relative expression of genes regulating ammonia accumulation during pathogenicity.

To determine the importance of $\mathrm{pH}$ sensitivity during the alkalinization process on the regulation of nitrogen-metabo-
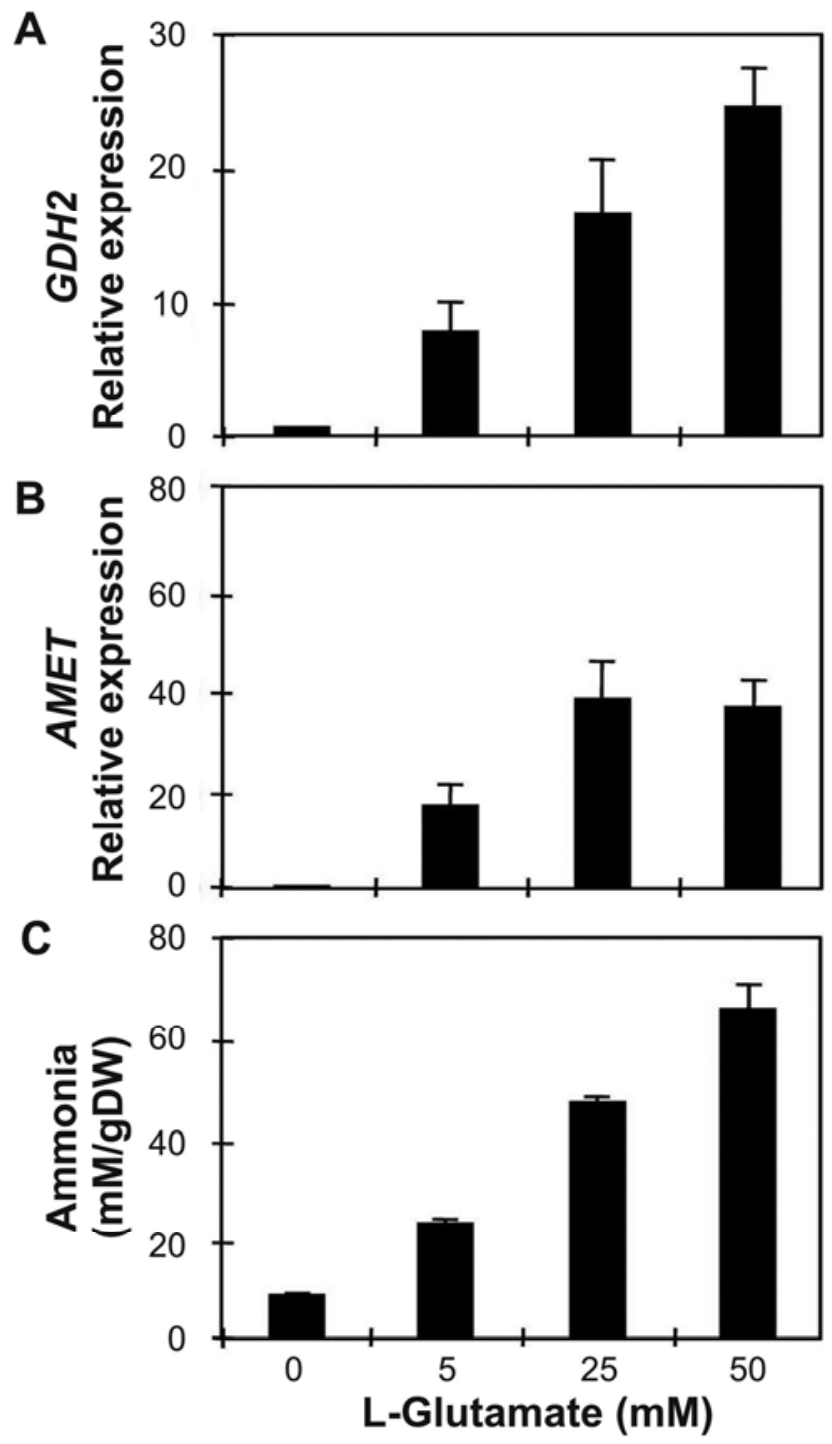

Fig. 2. Effects of L-glutamate on relative expression of Colletotrichum gloeosporioides GDH2 and AMET and ammonia accumulation. Relative expression of $\mathbf{A}, G D H 2$ and $\mathbf{B}, A M E T$ compared with that of $18 S$ ribosomal gene, determined by quantitative polymerase chain reaction analysis analysis of total RNA isolated from C. gloeosporioides mycelia, and $\mathbf{C}$, ammonia accumulation in the secondary medium (SM). Samples were taken $16 \mathrm{~h}$ after transfer to the SM amended with L-glutamate and buffered with phthalate buffer to $\mathrm{pH}$ 5.0. Averages of three replications \pm standard deviation are presented. lism genes determining ammonia accumulation, we used $C$. gloeosporioides $\Delta$ pacl loss-of-function mutants that have high sensitivity to alkalinization conditions (Miyara et al. 2008). When $\Delta$ pacl strains were grown in the SM amended with 50 $\mathrm{mM}$ glutamate at $\mathrm{pH} 6.0$ or were inoculated on avocado fruits, the relative expressions of $G S 1, M E P B$, and $G L T$, which are usually expressed during the alkalinization process, were all down-regulated, whereas expression of $G D H 2$, which is usually expressed under more acidic conditions, was up-regulated (relative to the wild-type [WT] strain) (Tables 3 and 4). Analysis of ammonia accumulation in the mycelium of the $\Delta p a c 1$ strains under those conditions showed a $60 \%$ greater accumulation than in the WT, accompanied by an increase in the $\mathrm{pH}$ by 0.5 units (Fig. 5). These results provide compelling evidence that ammonia metabolism is a $\mathrm{pH}$-dependent mechanism that is governed by the global $\mathrm{pH}$ regulator Pac1.

Functional analysis of $G D H 2$-disrupted mutants: relative expression of $\mathrm{GDH} 2$, ammonia accumulation, appressorium formation, and pathogenicity.

To assess the functions of $C$. gloeosporioides $G D H 2$ in ammonia accumulation, $G D H 2$ was inactivated by homologous recombination replacing the intact $G D H 2$ with a $g d h 2-5^{\prime}-H y g-$ gdh2-3' disruption cassette using the Gateway system (Shafran et al. 2008). Gene-disruption events were first analyzed by PCR screening for integration of the gdh2-5'-Hyg-gdh2-3'-cassette at the GDH2 locus (Fig. 6A and D). Two primer sets (GDH2 CON 5'F and GDH2 CON 3'R) (Table 5), designed on the basis of the region flanking the disruption cassette at the $5^{\prime}$ and $3^{\prime}$ ends, respectively, and primer set HYG (Table 5). In the case of homologous integration, an 800-bp amplicon (from the $5^{\prime}$ and $3^{\prime}$ region, respectively) is observed in the transformants $\Delta g d h 2_{640}, \Delta g d h 2_{680}$, and $\Delta g d h 2_{689}$, indicating integration of the
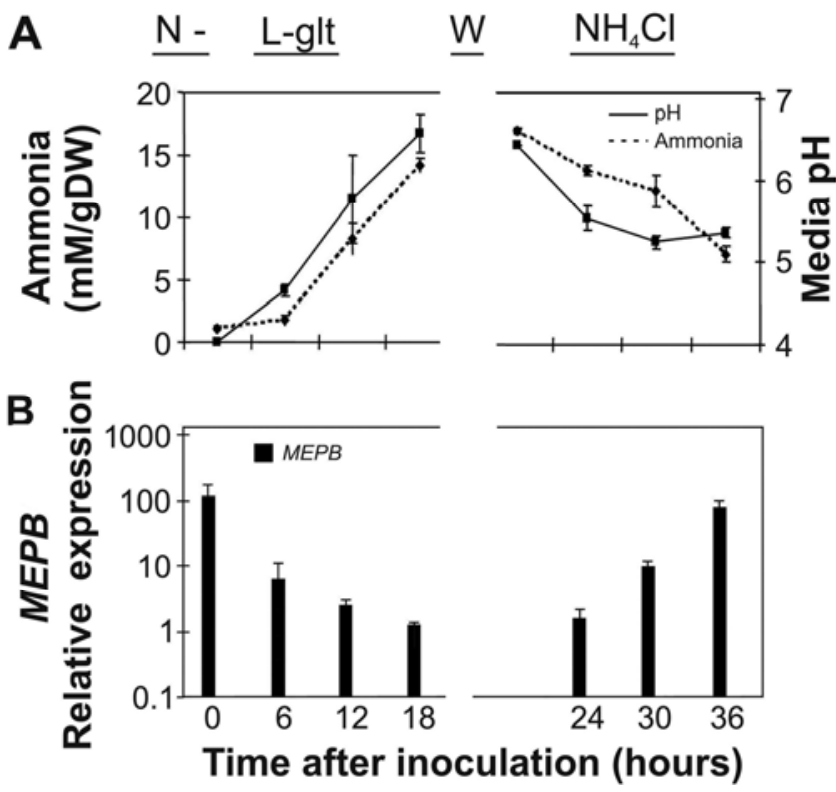

Fig. 3. Relationship between ammonia secretion, $\mathrm{pH}$, and relative expression of MEPB of Colletotrichum gloeosporioides, under various $\mathrm{pH}$ and nutritional conditions. $C$. gloeosporioides was grown in primary medium, the hyphal mat was transferred for $3 \mathrm{~h}$ to secondary medium (SM) without a nitrogen source, and was then transferred again to SM amended with 10 $\mathrm{mM}$ L-glutamate (L-glt) at $\mathrm{pH}$ 4.0. After $18 \mathrm{~h}$, the hyphae were washed (W) and transferred to a new SM amended with $10 \mathrm{mM} \mathrm{NH}_{4} \mathrm{Cl}$ at an initial $\mathrm{pH}$ of 6.5. A, Changes in ammonia accumulation and $\mathrm{pH}$ induced by $C$. gloeosporioides. B, Relative expression of $M E P B$ compared with that of the constitutive $18 S$ ribosomal gene, determined by quantitative polymerase chain reaction analysis of total RNA isolated from C. gloeosporioides mycelia. Averages of three replications \pm standard deviation are presented. 
A
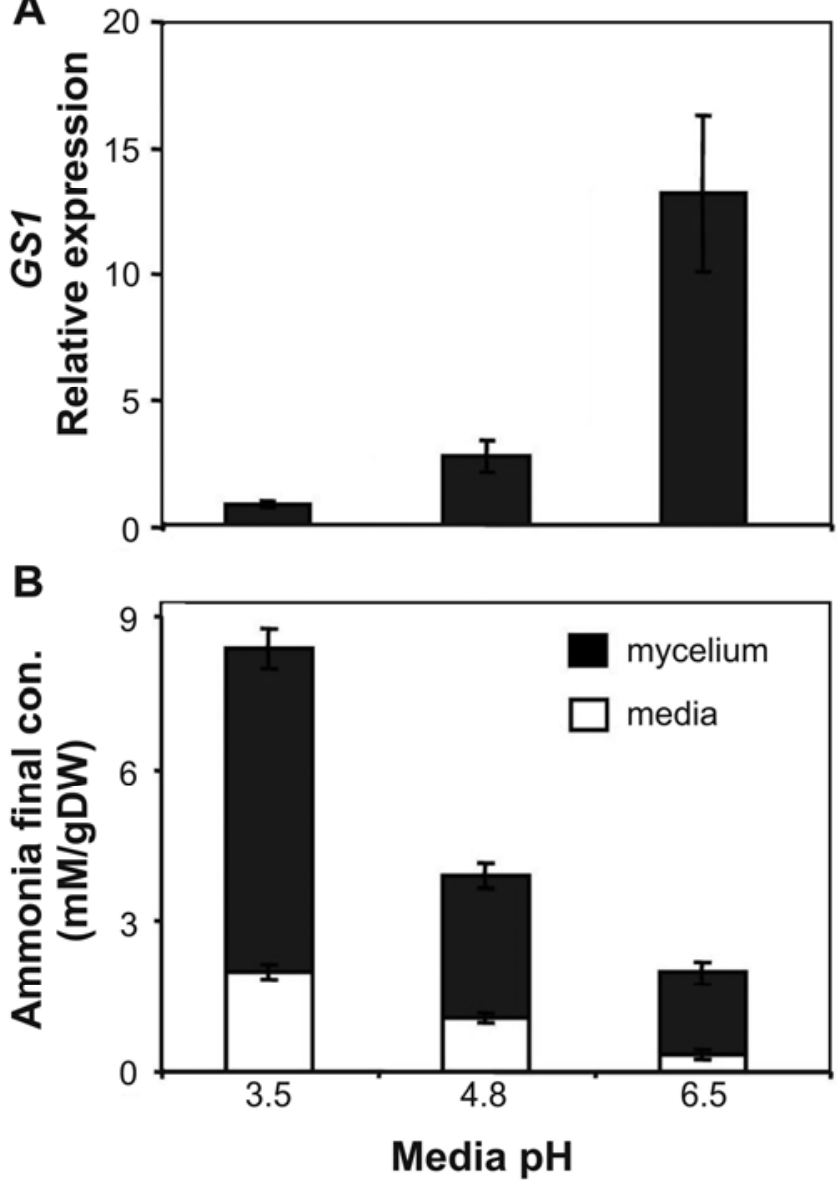

Fig. 4. Effects of $\mathrm{pH}$ on the relative expression of GS1 of Colletotrichum gloeosporioides and on ammonia levels. Relative expression of GS1 and ammonia residuals as a function of medium $\mathrm{pH}$ level were determined 16 $\mathrm{h}$ after transfer from primary medium to fresh secondary medium (SM) amended with $10 \mathrm{mM} \mathrm{NH}_{4} \mathrm{Cl}$ buffered with phthalate to different $\mathrm{pH}$ values. A, Expression of $G S 1$ relative to that of $18 S$ ribosomal gene, determined by quantitative polymerase chain reaction analysis of total RNA isolated from C. gloeosporioides mycelia. B, Residual ammonia in the media and inside the mycelia, as determined after grinding mycelia in the presence of water. Ammonia was detected in the supernatant and mycelium filtrate. Averages of three replications \pm standard deviation of one experiment out of three repeated experiments are presented. disruption cassette into the gdh2 locus. Ectopic strains Ectopic $_{610}$ and Ectopic 625 were negative for the desired PCR product, but they were positive for the 1,009-bp hygromycin fragment (primer set $\mathrm{HYG}$ ), suggesting random insertion of the cassette (Fig. 6A). Southern analysis of strains $\Delta g d h 2_{640}$, $\Delta g d h 2_{680}$, and $\Delta g d h 2_{689}$, using an internal probe from $g d h 2$, confirmed the PCR results (Fig. 6B). As expected, a single band of $550 \mathrm{bp}$ was detected in the WT strain that was absent from the $\Delta g d h$ disruption strains. Expected hybridization band patterns at 498, 724, and 1,780 bp for the gene-replacement event were identified for strains $\Delta g d h 2_{640}, \Delta g d h 2_{680}$, and $\Delta g d h 2_{689}$ (Fig. 6B). Relative expression of $G D H 2$ was detected in the WT and ectopic strains but was undetectable in the mutant strains.

$\Delta g d h 2$ strains did not exhibit differences in radial growth compared with the WT and Ectopic ${ }_{625}$ strains 2 days after inoculation in minimal agar medium supplemented with Lglutamine, but their growth was significantly restricted in the

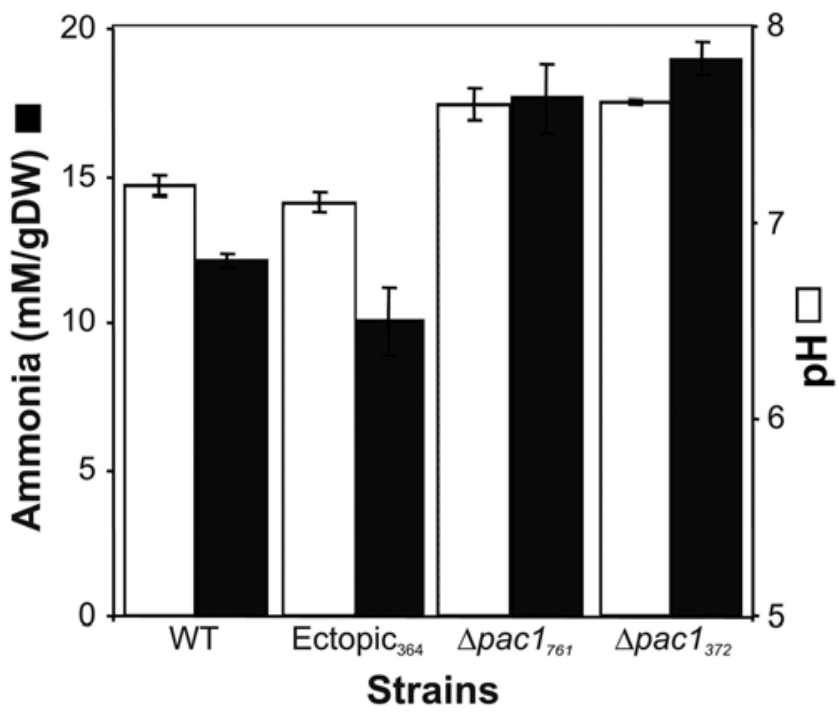

Fig. 5. Internal ammonia concentration and $\mathrm{pH}$ in the mycelia of Colletotrichum gloeosporioides $\triangle p a c 1$ (strains 761 and 372), wild type (WT), and Ectopic $_{364}$ strains. The level of ammonia and $\mathrm{pH}$ in the mycelium of $C$. gloeosporioides strains was tested $16 \mathrm{~h}$ after transfer from primary medium to nonbuffered SM amended with $50 \mathrm{mM}$ L-glutamate at $\mathrm{pH} 4.0$. The mycelia were ground in the presence of water. $\mathrm{pH}$ and ammonia were detected in the ground mycelial filtrate.

Table 3. Relative expression of genes modulating the accumulation of ammonia in $\Delta$ pacl and wild-type (WT) strains of Colletotrichum gloeosporioides grown in culture media

\begin{tabular}{lccccc}
\hline Strain/gene & $\boldsymbol{P A C \boldsymbol { I }}$ & $\boldsymbol{G D H} \mathbf{2}$ & $\boldsymbol{G S \boldsymbol { }}$ & $\boldsymbol{G L T}$ & $\boldsymbol{M E P B}$ \\
\hline WT & $0.84 \pm 0.24$ & $1.25 \pm 0.35$ & $0.88 \pm 0.15$ & $1.01 \pm 0.02$ & $1.17 \pm 0.24$ \\
Ectopic $_{364}$ & $0.56 \pm 0.04$ & $1.32 \pm 0.01$ & $0.58 \pm 0.08$ & $0.62 \pm 0.12$ & $0.98 \pm 0.38$ \\
Apacl $_{372}$ & $0.00 \pm 0.00$ & $3.21 \pm 0.96$ & $0.14 \pm 0.01$ & $0.00 \pm 0.00$ & $0.39 \pm 0.16$ \\
Spacl $_{761}$ & $0.00 \pm 0.00$ & $3.70 \pm 0.90$ & $0.21 \pm 0.03$ & $0.00 \pm 0.00$ & $0.22 \pm 0.02$ \\
\hline
\end{tabular}

${ }^{a}$ Relative expression levels as determined by quantitative polymerase chain reaction normalized against $18 S$ rRNA of $P A C l, G D H 2, G S 1, G L T$, and $M E P B$ genes in the WT, Ectopic $3_{364}, \Delta \mathrm{pacl}_{372}$, and $\Delta \mathrm{pacl}_{761}$ strains. The strains were cultured for 3 days in primary medium and were then transferred to secondary medium amended with L-glutamate and buffered to $\mathrm{pH} 6.0$ for a further $24 \mathrm{~h}$. The averages of three replications \pm standard deviation are presented.

Table 4. Relative expression of genes modulating the accumulation of ammonia by Colletotrichum gloeosporioides $\Delta$ pacl and wild-type (WT) strains inoculated on avocado fruit ${ }^{\mathrm{a}}$

\begin{tabular}{|c|c|c|c|c|}
\hline Strain/gene & $G D H 2$ & GS1 & $G L T$ & $M E P B$ \\
\hline WT & $0.96 \pm 0.04$ & $1.14 \pm 0.21$ & $0.97 \pm 0.03$ & $0.92 \pm 0.10$ \\
\hline $\operatorname{ppacl}_{761}$ & $2.16 \pm 0.10$ & $0.65 \pm 0.14$ & $0.00 \pm 0.00$ & $0.12 \pm 0.04$ \\
\hline Uninfected fruit & $0.00 \pm 0.00$ & $0.00 \pm 0.00$ & $0.00 \pm 0.00$ & $0.00 \pm 0.00$ \\
\hline
\end{tabular}

a Relative expression levels, as determined by quantitative polymerase chain reaction normalized against $18 S$ rRNA of $G S 1, G D H 2, G L T$, and $M E P B$ genes, in the decayed mesocarp of infected avocado cv. Fuerte fruit tissue. To assess decay development, mycelia of $C$. gloeosporioides WT and $\triangle p a c l_{761}$ strains were cultured for 3 days in primary medium and then washed twice with sterile water. The washed mycelia were bulk-inoculated in the mesocarp and were incubated at $22^{\circ} \mathrm{C}$ under high humidity. The averages of three replications \pm standard deviation are presented. 
presence of L-glutamate as the sole carbon or nitrogen source (results not shown). The dynamics of ammonia accumulation was assessed in the 3-day hyphal mat of WT, $\Delta g d h 2$, and Ectopic $_{625}$ strains that were transferred to acidified SM amended with glutamate for an additional $24 \mathrm{~h}$ (Fig. 7). A similar increase in ammonia accumulation, up to $80 \mathrm{mM}$ per gram of dry weight (DW), and an increase of $2.7 \mathrm{pH}$ units were observed in the WT and Ectopic ${ }_{625}$ strains compared with minor changes in ammonia accumulation and $\mathrm{pH}$ with the $\Delta g d h 2 \mathrm{mu}-$ tants (Fig. 7). However, growth of the $\Delta g d h 2$ mutant in SM amended with L-glutamine but not L-glutamate did restore some of the ammonia secretion and induced a $\mathrm{pH}$ increase by $\Delta g d h 2$ strains (results not shown).

Analysis of $G D H 2$ in WT and $\Delta g d h 2$ strains, ammonia accumulation, and its effect on appressorium formation and host colonization.

Microscopic observations of spores of the WT strain $5 \mathrm{~h}$ after the induction of germination showed a strong internal fluores- cence signal, as detected by using the alkaline detector fluorescence dye BCECF, while a fluorescence signal was hardly detected in the ammonia production-impaired $\Delta g d h 2$ strains (Fig 8A). Analysis of the relative expression of $G D H 2$ at different stages after spore germination in the WT strain indicated that germinating spores producing appressoria show 227- and 20fold higher levels of $G D H 2$ expression and ammonia accumulation, respectively, than germinating spores producing germ tube only (Fig. 8B). Fivefold dilution of the spores of the WT (Fig. 8C) and $\Delta g d h 2$ mutant spores (Fig. 8D and E) subjected to germination conditions resulted in a marked reduction, by 25 to $50 \%$, in the percentage of total and mature appressorium formation, while addition of external ammonia $\left(5 \mathrm{mM} \mathrm{NH}_{4} \mathrm{Cl}\right)$ under the same conditions restored appressorium formation (Fig. 8C and E).

Colonization of the avocado fruit pericarp by the $\Delta g d h 2$ strains was attenuated by 40 to $50 \%$ relative to the WT, 5 days after inoculation (Fig. 9A). Under these conditions, the $\Delta g d h 2$ strains showed a $66 \%$ reduction in appressorium formation

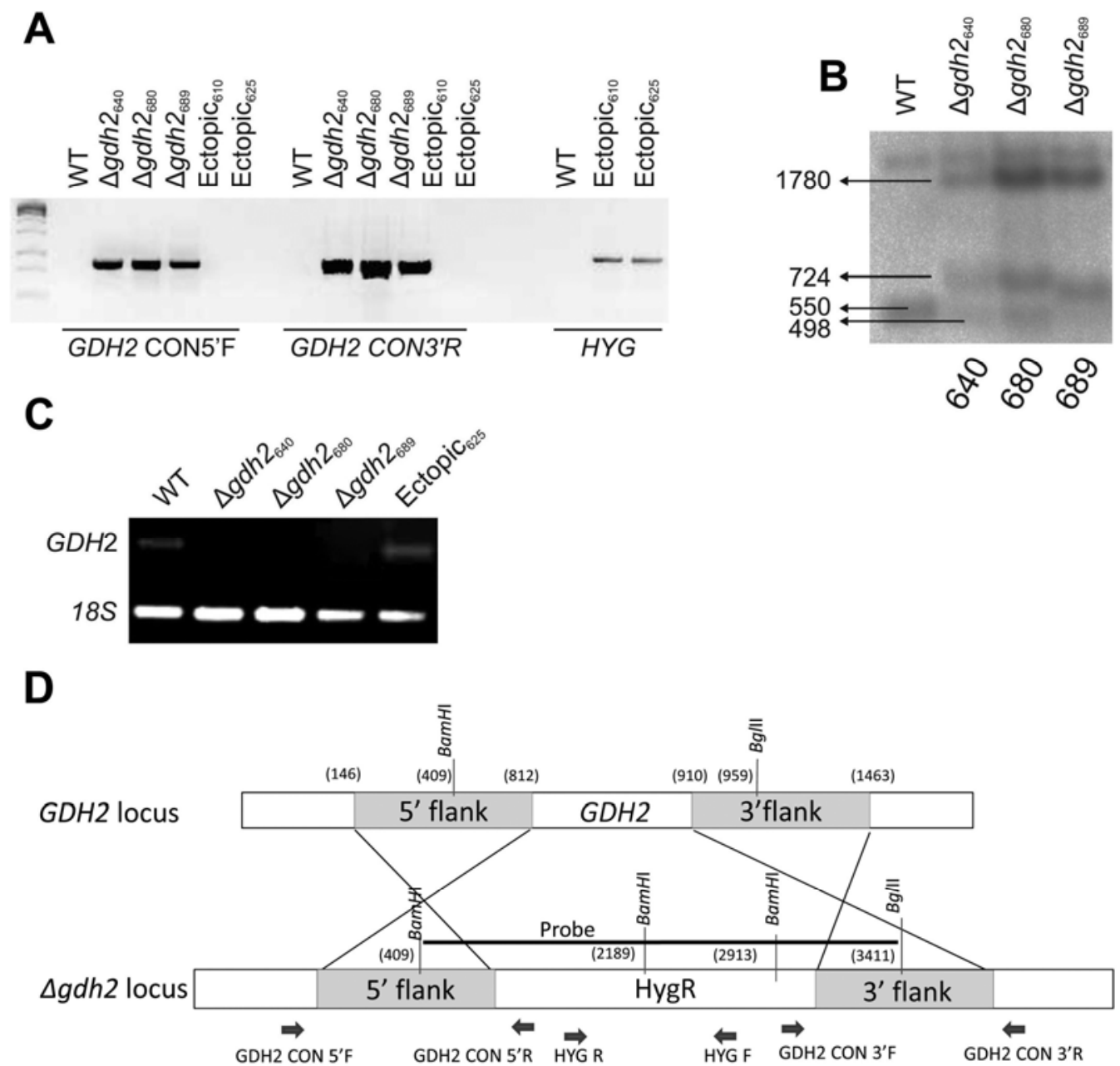

Fig. 6. Construction and analysis of $G D H 2$ gene-disruption transformants. A double crossing-over homologous recombination event resulting in replacement of the original GDH2 sequence with the disrupted $g d h 2: h y g R$ cassette. A, Polymerase chain reaction (PCR) analysis of the wild type (WT) and potential independent GDH2-disruption colonies. Primer set GDH2 CON 5'F positioned upstream of the GDH2:HYG3 region and a reverse primer located on the hygromycin cassette were used to identify positive gene replacement at the $5^{\prime}$ locus. Primer set GDH2 CON 3'R from the hygromycin cassette and primers downstream of the GDH2:HYG3 region were used to identify gene replacement at the $3^{\prime}$ locus. Primer set $\mathrm{HYG}$, R and F were used as a positive control for the ectopic strains, to confirm random integration of the $G D H 2: H Y G 3$ cassette. B, Southern analysis of the WT and deletion strains $\Delta g d h 2_{640}, \Delta g d h 2_{680}, a n d$ $\Delta g d h 2_{689}$. Genomic DNA of selected strains was digested with BamHI, separated in a 0.8\% agarose gel, blotted, and probed with the 457-bp PCR product of the $g d h 2$ region. A successful deletion by gene replacement is demonstrated by the absence of the WT band at 550 bp for the GDH2-disrupted strains. Expected hybridization band patterns by BglII and BamHI digestion for $G D H 2$-disrupted strains are 498, 724, and an additional upper band at 1,780 bp. C, Expression of $G D H 2$ in the $\Delta g d h 2$ strains compared with the ectopic-integration control and WT strains, as detected by semiquantitative PCR. Cultures were initially grown in $\mathrm{M}_{3} \mathrm{~S}$-rich medium and were subsequently transferred to broth minimal medium supplemented with 5 mM glutamate for 16 h, prior to RNA extraction. D, Scheme describing gene disruption. 
$(85 \pm 9.7 \%$ in the WT compared with $38 \pm 8.3 \%$ in the $\Delta g d h 2$ mutant), and $84 \%$ less mature appressoria ( $85 \pm 10 \%$ in the WT compared with $14 \pm 5 \%$ in the $\Delta g d h 2$ mutant). Interestingly, no differences in colonization between the mutant and the WT strains were observed when inoculation was carried out directly on the mesocarp (Fig. 9B), conditions that do not induce appressorium formation by the fungus (Prusky 1996).

\section{DISCUSSION}

Genes induced by environmental pH in C. gloeosporioides.

A cDNA macroarray platform and qPCR were used to identify the regulatory machinery contributing to the alkalinization process during the necrotrophic development of C. gloeosporioides. A set of genes that were differentially expressed during fungal growth at $\mathrm{pH} 4.0$ to 4.5 and at $\mathrm{pH} 6.0$ to 7.0 was identified; it included genes involved in nitrogen, ammonia, and carbon metabolism, as well as genes corresponding to alkaline $\mathrm{pH}$ tolerance. Genes encoding the production and export of ammonia, such as $G D H 2$ and $A M E T$, were expressed initially at $\mathrm{pH} 4.0$, whereas those coding for ammonia import and inner mycelial regulation, such as MEP, MEPB, GLT, and GS1, were strongly expressed under alkaline conditions. Carbonmetabolism genes, such as succinate semialdehyde dehydrogenase and the two sugar transporters MATA and HXT2, were expressed at low $\mathrm{pH}$, whereas phosphoenolpyruvate carboxykinase, the key gene in gluconeogenesis, and its activator, glucose-repressible protein ( GRG1), showed increased expression under the more alkaline conditions. The transcript DFG5 homolog, a cell-wall glycoprotein known to modulate tolerance to high pH in Candida albicans (Plaine et al. 2008; Spreghini et al. 2003), was also strongly activated (4,126-fold) in $C$. gloeosporioides under alkalinization conditions. In S. cerevisiae, this same gene activates a mitogen-activated protein (MAP) kinase module that controls part of the transcriptional adaptive response of the cell to high pH (Jung and Levin 1999). Other genes that have been reported in filamentous fungi and yeast as required for adaptation to alkalinization conditions-calcineurin binding protein $(C P B)$ and $\mathrm{Ca}^{2+}$-binding protein $(C D C 4)$ (Schumacher et al. 2008; Viladevall et al. 2004)—were also expressed by $C$. gloeosporioides under alkaline conditions. These genes are activated in yeast colonies exposed to alkaline inducers, i.e., conditions that trigger a strong, transient intercellular calcium burst (Viladevall et al. 2004).

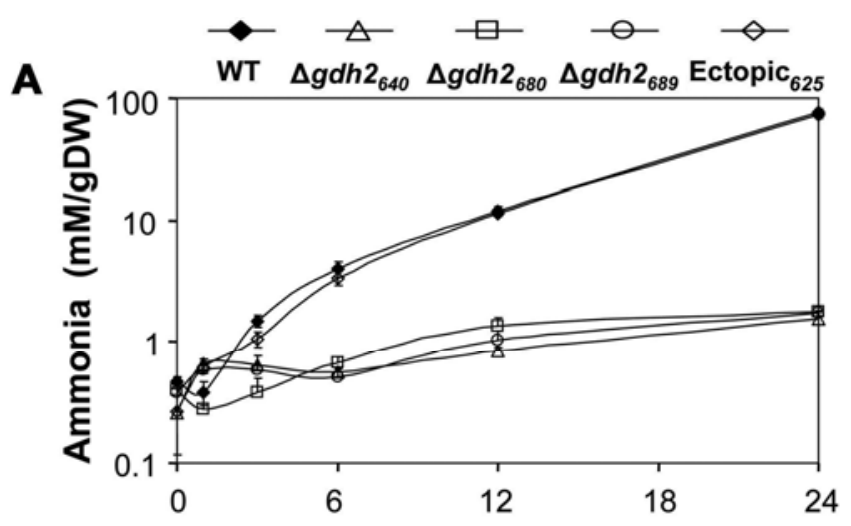

B

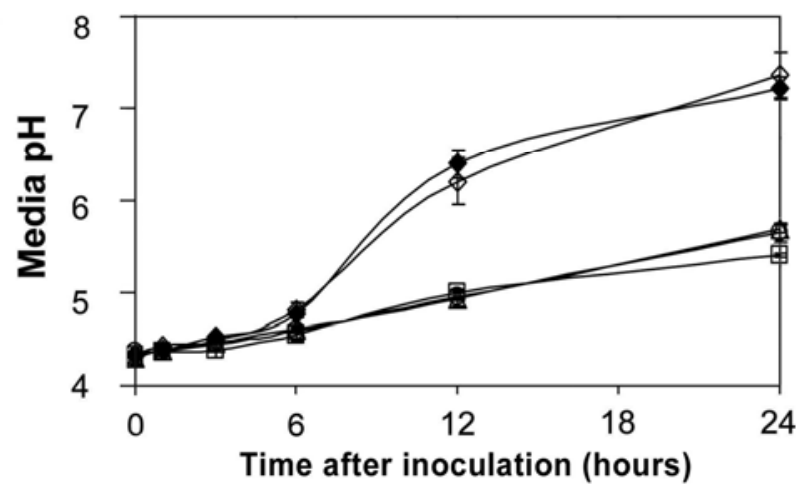

Fig. 7. $\mathrm{pH}$ changes and ammonia accumulation induced by wild type (WT), Ectopic ${ }_{625}$, and $\Delta g d h 2$ Colletotrichum gloeosporioides strains. A, Ammonia concentration and $\mathbf{B}, \mathrm{pH}$ values. Spores of $C$. gloeosporioides were inoculated into primary medium and, 3 days later, were transferred to secondary medium amended with glutamate, and were then analyzed at different periods after inoculation into ammonia-inducible media. Average of three replications \pm standard deviation of one experiment out of three repeated experiments is presented.

Table 5. Primers used throughout this study ${ }^{\mathrm{a}}$

\begin{tabular}{|c|c|c|c|}
\hline Primer name & Suffix & Forward seq. $\left(5^{\prime} \rightarrow 3^{\prime}\right)$ & Reverse seq. $\left(5^{\prime} \rightarrow 3^{\prime}\right)$ \\
\hline$\overline{\text { DFG5 }}$ & qRT & GCCCCTGCGACCAACTCTA & TGATCGGCGAAAACTCACG \\
\hline GS1 & qRT & GCGACCCTCAAGCTTCTTGA & CGGTCTGCACAGCAACTTCTC \\
\hline GDH2 & qRT & AGAATCGGCGCAACTCTGTT & CGTGTATCCCAGCCTTAACGAA \\
\hline GDH2-5'C & CLO & $\begin{array}{l}\text { (AttB4)GGGGACAACTTTGTATAGAAAAGTTGGCGG } \\
\text { CCGCCCCGGCATTAAGAACCCTA }\end{array}$ & $\begin{array}{l}\text { (AttB1)GGGGACTGCTTTTTTGTACAAACTTGGTGGA } \\
\text { CTTGCCATCCTTGAT }\end{array}$ \\
\hline GDH2-3'C & CLO & $\begin{array}{l}\text { (AttB2)GGGGACAGCTTTCTTGTACAAAGTGGGGTG } \\
\text { GTGTCACCTCTTCCT }\end{array}$ & $\begin{array}{l}\text { (AttB3)GGGGACAACTTTGTATAATAAAGTTGGCGG } \\
\text { CCGCCCATTAACGAACCCCAAAAA }\end{array}$ \\
\hline AttB-HYG & CLO & $\begin{array}{l}\text { (AttB1HYG)GGGGACAAGTTTGTACAAAAAAGCAG } \\
\text { GCTCCCGGGCTGCAGGAATTCGAT }\end{array}$ & $\begin{array}{l}\text { (AttB2HYG)GGGGACCACTTTGTAC-AAGAAAGCTG } \\
\text { GGTAATTAACCCTCACTAAAGGGAA }\end{array}$ \\
\hline $\mathrm{GDH} 2 \mathrm{CON} 5^{\prime} \mathrm{F}$ & $\mathrm{CON}$ & ATCCTTCTCGACCCCAAGAT & GCCTGGACGACTAAACCAAA \\
\hline GDH2 CON 3'R & $\mathrm{CON}$ & CTGGATCCATCTCCTTGCAT & GTGCCCTCTCTTGCTTTTTG \\
\hline GDH-P & PRO & АTCCTTCTCGACCCCAAGAT & GGATCTGCTCGTTCTTCCAG \\
\hline HYG & $\mathrm{CON}$ & CAAACAGCTTGATGAACTGT & GCCTGGACGACTAAACCAAA \\
\hline GLT & qRT & GATCGCTGTTCCGTCCATGT & GAGACGCTCAAGGTTCCCAAC \\
\hline HP1 & qRT & TTCTTCTTGGGCGCCTTT & TGTCTCACCACAGCAATGACAG \\
\hline $\mathrm{CDC} 4$ & qRT & TCGTACAACTCGCTCGAATGC & CTCGTCCGCACCATTCTT \\
\hline CAL & $\mathrm{qRT}$ & AGTCCTGGTTCACCGCCTATC & GGACGCATGAGGAACCAAGT \\
\hline AMET & qRT & AAGACGGGAACCTGGAAGAAG & GCTAGCAGCATTCCTGGCAT \\
\hline $18 \mathrm{~S}$ & qRT & GTGAGGCCCTCAAAGGTAGTGG & GGATCCCAGTGCGAGACGT \\
\hline MEPB-Q & qRT & GTCCCGCCCTCGCTCTTG & TGCCTGTCCAGGTCCAGTAAG \\
\hline MEPB-C & CLO & TTCCACTGGTTYTTCTGGGGATACTCA & TAGTGRTGRTTGATCCAGCC \\
\hline PAC1 & qRT & CTGTCTACGAAAACGCGAACC & AAGGGCTGTTGCGGAGATC \\
\hline SSD & gRT & TGAGGCCGGTGTTGACG & AAAGACATCTCCCGCGTGAT \\
\hline PELB & qRT & CCGTCTTCTCCGACACCAA & CGAGGTCGACGTCATTGACA \\
\hline
\end{tabular}

${ }^{a}$ qRT refers to primers used in real-time quantitative polymerase chain reaction experiments, CLO refers to primers used in gene cloning, CON for mutant confirmation, and PRO for probe amplification. 
One of the most abundant clones (5.7\% of the total) discovered during quality control of the cDNA libraries was CAP5 (U18757). This gene was strongly expressed at the various $\mathrm{pH}$ levels, and it contained an open reading frame coding for a 27 amino acid cysteine-rich peptide with homology to the metallothioneins expressed in the conidia; it may have a role during host penetration (Hwang and Kolattukudy 1995). The secretion of ammonia and alkaline conditions during early stages of germination (Diéguez-Uribeondo et al. 2008) may activate this gene and its homologs, C. gloeosporioides CAP3, and Magnaporthe grisea $M M T 1$, thereby enabling or enhancing, or both, fungal penetration (Hwang and Kolattukudy 1995; Tucker et
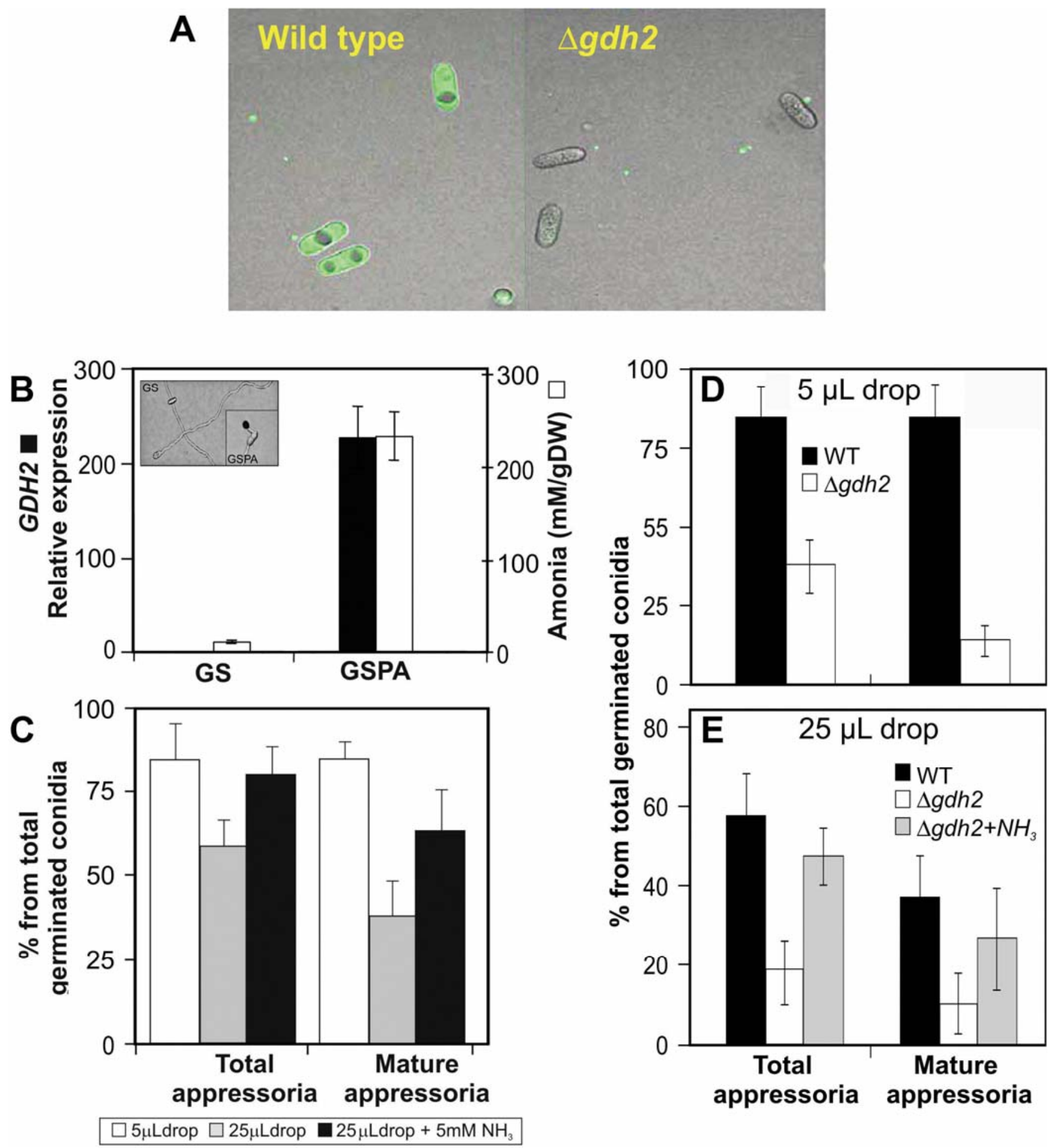

Fig. 8. Relationship between relative expression of GDH2, ammonia accumulation and appressorium development by Colletotrichum gloeosporioides spores. A, Alkalinization determined by fluorescence of wild type (WT) and spores from $\Delta g d h 2$ strains, using BCECF dye $5 \mathrm{~h}$ after germination induction on a hard surface. B, Relative expression of $G D H 2$, as determined by comparison with the $18 S$ ribosomal gene, detected by quantitative polymerase chain reaction analysis of total RNA isolated from C. gloeosporioides, and ammonia accumulation of germinating spores (GS) and germinating spores producing appressoria (GSPA) (inset). C, $\mathbf{D}$, and $\mathbf{E}$, Total and mature appressorium formation as affected by either fivefold dilution in water or addition of $5 \mathrm{mM} \mathrm{NH} \mathrm{Cl}_{\mathrm{in}}$ the WT $(\mathrm{C})$ and $\Delta g d h 2 \mathrm{strain}(\mathrm{D}$ and E). Spores $\left(5 \mu \mathrm{l}, 10^{6}\right.$ spore $\left.\mathrm{ml}^{-1}\right)$ were counted directly or diluted fivefold in water. Addition of $\mathrm{NH}_{4} \mathrm{Cl}$ was carried out by placing a drop of $5 \mathrm{mM} \mathrm{NH} \mathrm{m}_{4} \mathrm{Cl}$ at a distance of $5 \mathrm{~mm}$ from the spore supension drop. The averages of three replications \pm standard deviation are presented. 
al. 2004). It is still not clear what roles the carbon- and MAP kinase-regulated genes play in $C$. gloeosporioides during the alkalinization process; this will be addressed in a future study.

Ammonia production, export, and uptake in Colletotrichum.

One of the key genes involved in the synthesis of ammonia, $G D H 2$, which catalyzes oxidative deamination of the amino acid glutamate to ammonia, was strongly induced by low $\mathrm{pH}$ and increased glutamate content in the growth medium. Low $\mathrm{pH}$ conditions also activated the $C$. gloeosporioides AMET, a homolog of the yeast Ato proteins (from the $\mathrm{YaaH}$ family) that function as ammonium exporters in yeast colonies (Palkova et al. 2002; Ricicova et al. 2007).

\section{Genes related to ammonia uptake and balance in the mycelia.}

In C. gloeosporioides, two groups of transporters that contribute to the final ammonia concentration inside the hyphae were found to be activated at $\mathrm{pH} 6.0$ to 7.0 , i.e., the methyl ammonium and glutamate transporters. The $80 \%$ increase in the relative expression of $M E P$ and $M E P B$ under alkaline conditions was similar to that reported in yeast and other fungal systems (Monahan et al. 2006; Teichert et al. 2008; Zikanova et al. 2002). GLT, a transporter that enhances glutamate uptake, was also enhanced under alkaline conditions, and it, too, contributes to ammonia concentration inside the hyphae. The uptake of ammonia and its accumulation in the hyphae raised the $\mathrm{pH}$ by 0.5 units and promoted the activation of GS1. Glutamine synthase (GS) plays a key role in amino-acid metabo-

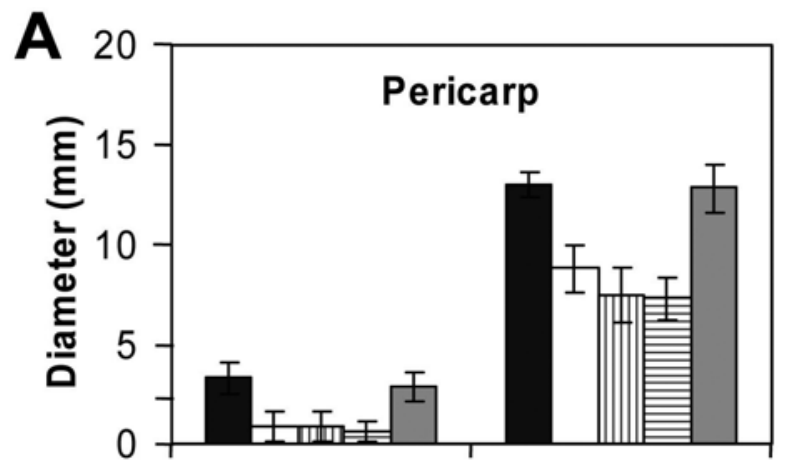

B

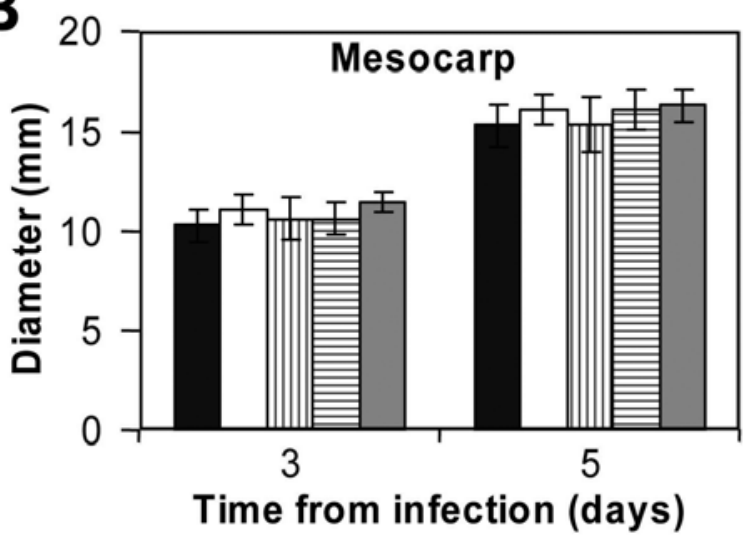

$\square$ WT $\square \Delta g d h 2_{640}$ 血 $\Delta g d h 2_{680}$ 目 $\Delta g d h 2_{689} \square$ Ectopic $_{625}$

Fig. 9. Pathogenicity assays of Colletotrichum gloeosporioides wild type (WT), ectopic, and $\Delta g d h 2$ mutant strains. Inoculation of $\mathbf{A}$, pericarp or $\mathbf{B}$, mesocarp of freshly harvested (and peeled for mesocarp) avocado cv. Fuerte fruits. The inoculated fruits were incubated for $24 \mathrm{~h}$ at $22^{\circ} \mathrm{C}$ under high humidity and, 3 and 5 days later, lesion development was monitored. The average data for 10 infected fruits \pm standard deviation are reported. lism; it regulates the level of ammonia by catalyzing the condensation of ammonium ion and glutamate to yield glutamine. This reaction is also considered a mechanism for ammonia reassimilation and detoxification (Stephenson et al. 1997).

To determine the importance of $\mathrm{pH}$ sensitivity to differential transcript expression during the alkalinization process by $C$. gloeosporioides, we used the $\Delta$ pacl loss-of-function mutants, which are highly sensitive to alkalinization conditions. Under these conditions, during both pathogenicity on avocado fruit and growth in culture, the $\Delta p a c 1$ mutant strains exhibited upregulation of $G D H 2$ (the acid-expressed gene) and downregulation of $G S 1, G L T$, and $M E P B$ (the alkaline-expressed genes). This was in contrast to the differential expression of acid and alkaline genes in the WT strain and confirmed the $\mathrm{pH}$ dependence of ammonia accumulation in C. gloeosporioides during pathogenicity, as observed previously for Aspergillus nidulans (Caddick et al. 1986; Penalva et al. 2008).

Taken together, our findings show that at low $\mathrm{pH}$ levels, $G D H 2$ contributes to the synthesis of ammonia produced by the pathogen; we assume that the ammonia is then exported by a specific ammonia exporter, $A M E T$, thereby increasing the external $\mathrm{pH}$. In a dynamic environment, at higher $\mathrm{pH}$ levels, ammonia is reassimilated by activation of methyl ammonium transporters together with an independent glutamate-based assimilation mechanism that is modulated by $G L T$. The final level of ammonia within the hyphae is regulated by its transformation to the amino acid glutamine by $G S 1$, which regulates the level of ammonia inside the hyphae and promotes ammonia detoxification (Hess et al. 2006; Stephenson et al. 1997).

\section{What are the functional implications of ammonia-metabolism genes for fungal growth and pathogenicity?}

Effect of ammonia on appressorium formation: The strong expression of $G D H 2$ at the initial stage of spore germination suggests that the supply of nutrients for the initial germination and appressorium formation is affected by endogenous resources (Horowitz-Brown et al. 2008; Solomon et al. 2003) and involves the degradation and recycling of stored lipids, carbohydrates, and nitrogen sources such as glutamate (Hao and Schmit 1991; Schmit and Brody 1975). This spore activity is very important, since the host surface is usually lacking many available soluble nutrients (Horowitz et al. 2006; Talbot et al. 1993). Nitrogen metabolism is not only a source of nutrients for germination. Ammonia accumulation has a direct effect on fungal appressorium formation and differentiation responses that affect pathogenicity. i) Appressorium formation was accompanied by high relative expression of GDH2 (200-fold increase) and ammonia accumulation (up to $200 \mathrm{mM}$ per gram of DW). ii) Reduced ammonia levels by spore dilution reduced appressorium formation, while exogenous addition of ammonia

Table 6. Strains of Colletotrichum gloeosporioides used in this work

\begin{tabular}{|c|c|}
\hline Code & Isolate \\
\hline WT & C. gloeosporioides wild type Cg14 (Wattad et al. 1995) \\
\hline Apacl $_{761}$ & C. gloeosporioides spacl $_{761}$ (Miyara et al. 2008) \\
\hline Apacl $_{372}$ & C. gloeosporioides $\Delta$ pacl $_{372}$ (Miyara et al. 2008) \\
\hline Ectopic $_{364}$ & $\begin{array}{l}\text { C. gloeosporioides PAC1 ectopic integration no. } 364 \\
\text { (Miyara et al. 2008) }\end{array}$ \\
\hline$\Delta g d h 2_{640}$ & C. gloeosporioides $\Delta g d h 2_{640}$ (this work) \\
\hline$\Delta g d h 2_{680}$ & C. gloeosporioides $\Delta g d h 2_{680}$ (this work) \\
\hline$\Delta g d h 2_{689}$ & C. gloeosporioides $\Delta g d h 2_{689}$ (this work) \\
\hline Ectopic $_{625}$ & $\begin{array}{l}\text { C. gloeosporioides } \mathrm{GDH} 2 \text { ectopic integration no. } 625 \\
\text { (this work) }\end{array}$ \\
\hline Ectopic $_{610}$ & $\begin{array}{l}\text { C. gloeosporioides GDH2 ectopic integration no. } 610 \\
\text { (this work) }\end{array}$ \\
\hline
\end{tabular}


restored appressorium formation. iii) $\Delta g h d 2$ mutant strains showed reduced appressorium formation compared with the WT and in spore dilutions; in both cases, exogenous addition of ammonia restored appressoria formation. iv) $\Delta g h d 2$ mutant strains showed reduced colonization on avocado pericarp, in which appressorium formation is needed for penetration (Prusky 1996). However, the WT and $\Delta g h d 2$ strains showed no differential colonization of the fruit mesocarp, in which appressoria are not needed for colonization and nutrients are readily available on the fruit flesh. This indicates that the effect of ammonia on germ-tube differentiation is primarily the result of a nutrient signal that activates the nitrogen metabolism. In cases in which readily available nutrients are present, such as glutamine, the fungus will develop a germination pattern without appressoria that will not attack the host (Barhoom and Sharon 2004; Horowitz et al. 2006). $\Delta g h d 2$ strains of $M$. grisea have also been reported to affect appressorium formation; however, in that case, ammonia was not considered a key factor in their formation (Oh et al. 2008). In S. cerevisiae, ammonia release produced by amino acid-catabolic enzymes also affects morphological development and controls the transition from budding colonies to the filamentous phase (Palkova et al. 2002; Zikanova et al. 2002), suggesting the importance of ammonia production in signaling development of the hyphal structure.

Functional implications of the $\mathrm{pH}$ dependence of ammoniametabolism genes for Colletotrichum colonization. Colletotrichum spores must complete several developmental stages on the host surface before they can penetrate the host tissue (Nesher et al. 2008) and colonize it. This sequence of events includes germ-tube initiation, polar growth coupled with a limited number of cell divisions, arrestation of polar growth, and differentiation of an appressorium. We envision two possible effects of ammonia on Colletotrichum development in planta, i.e., the induction of appressoria formation during the biotrophic stage and the contribution to cell death during the necrotrophic stage. Accumulation of ammonia by the germinating spore and induction of appressorium formation is important for the activation of initial stages of fungal penetration and quiescence. This can be done through the accumulation of proper substrates such as NADH-NADPH as a result of the activation of $G D H 2$, which could activate NOX genes needed for appressoria formation (Benavente and Jacobson 2008). During the necrotrophic stage, the early accumulation of ammonia resulting from the expression of $G D H 2$ by the pathogen, may contribute to enhanced host cell death and the initiation of fungal colonization (Alkan et al. 2009). Studying the nitrogen metabolism in bean leaves, Pageau and associates (2006) claimed that there is differential induction of $G D H(2)$ and $G S 1$ markers in the leaves according to the respective compatible or incompatible host response induced by the pathogen. Although ammonia accumulation in the tissue was not tested in those cases, it was reported that, while $G D H(2)$ was induced in the host when cell death was triggered, GSI was preferentially induced when the plant-bacterium or -fungus (Colletotrichum lindemuthianum) relationships were incompatible (Tavernier et al. 2007), suggesting the importance of ammonia detoxification for biotrophic interactions. On the other hand, during the necrotrophic colonization of avocado fruits by $C$. gloeosporioides, during which activation of $G D H 2$ results in the accumulation of ammonia up to $3.5 \mathrm{mM}$, a pH increase to 8.2, and cell death (Alkan et al. 2009), alkaline conditions also activated the ammoniadetoxification process by $G S 1$ and, thereby, also contributed to the colonization process and glutamine accumulation. The overall results suggest that Pac1 activates not only gene expression of fungal pathogenicity factors such as PELB (Miyara et al. 2008) but also genes modulating ammonia accumulation inside and outside the hyphae. Accumulation of ammonia by the germinating spores, the appressoria, and the colonizing hyphae might be an important factor in cross-talk interactions, leading to the activation of quiescent infection of $C$. gloeosporioides in ripening fruits. Modulation of processes regulating ammonia accumulation, as found in host plants (Pageau et al. 2006) or as reported here for fungal pathogens, may contribute to the rapid colonization of the host fruits and the transition from biotrophic-quiescent to active-necrotrophic infection.

\section{MATERIALS AND METHODS}

\section{Fungal isolate, media, and growth conditions.}

Single-spore cultures of the WT Cg-14 isolate of C. gloeosporioides, obtained from a decayed avocado fruit (Persea americana cv. Fuerte) in Israel and all the $C$. gloeosporioides mutant strains used in this work (Table 6) were routinely cultured on $\mathrm{M}_{3} \mathrm{~S}$ agar (Tu 1985). $\mathrm{M}_{3} \mathrm{~S}$ medium without agar (primary medium) was also used for the initial growth of the fungus, prior to exposing it to different nutritional induction factors, and it contained the following reagents (per liter): 2.5 g $\mathrm{MgSO}_{4} \cdot 7 \mathrm{H}_{2} \mathrm{O}, 2.7 \mathrm{~g} \mathrm{KH}_{2} \mathrm{PO}_{4}, 1.0 \mathrm{~g}$ Bacto peptone, $1.0 \mathrm{~g}$ Bacto yeast extract (Difco, Detroit), $10 \mathrm{~g}$ sucrose, and $250 \mathrm{mg}$ chloramphenicol. The cultures were incubated at 22 to $24^{\circ} \mathrm{C}$ in a shaking incubator at $150 \mathrm{rpm}$ for 3 days and were harvested by filtration through a sterile Büchner funnel fitted with filter paper. The hyphal mat was washed twice with $40 \mathrm{ml}$ of sterile distilled water. The washed mycelia were resuspended in 40 $\mathrm{ml}$ of fresh SM containing the following reagents (per liter): 4 $\mathrm{g} \mathrm{K}_{2} \mathrm{HPO}_{4}, 2 \mathrm{~g} \mathrm{MgSO}_{4} \cdot 7 \mathrm{H}_{2} \mathrm{O}, 0.3 \mathrm{~g} \mathrm{CaCl}_{2} \cdot 2 \mathrm{H}_{2} \mathrm{O}, 10 \mathrm{mg} \mathrm{FeCl}$, and $50 \mathrm{mM}$ glucose. For the in vitro library construction, $1 \%$ (wt/vol) avocado cell wall (Eshel et al. 2002) was added instead of glucose. Different nitrogen sources, such as L-glutamine or L-glutamate sodium salt, were added to the SM according to the experiment, as described above. To monitor ammonia consumption, $\mathrm{SM}$ was amended with $\mathrm{NH}_{4} \mathrm{Cl}$ (Sigma, St. Louis) as a nitrogen source (ammonia-consuming medium). The medium was buffered with $50 \mathrm{mM}$ phthalate-hydroxide buffer (Sigma) to obtain an initial $\mathrm{pH}$ between 4.0 and 6.0. In some cases, unbuffered medium was acidified using $1 \mathrm{~N} \mathrm{HCl}$. In some experiments, $1 \%$ (wt/vol) yeast extract medium was used. This medium contained the following reagents (per liter): $5 \mathrm{~g} \mathrm{KNO}_{3}, 4 \mathrm{~g} \mathrm{~K}_{2} \mathrm{HPO}_{4}, 2 \mathrm{~g} \mathrm{MgSO}_{4} \cdot 7 \mathrm{H}_{2} \mathrm{O}, 0.3 \mathrm{~g} \mathrm{CaCl}_{2} \cdot 2 \mathrm{H}_{2} \mathrm{O}$, $10 \mathrm{mg} \mathrm{FeCl}$, and $10 \mathrm{~g} \mathrm{Bacto}$ yeast extract, adjusted with $\mathrm{HCl}$ to $\mathrm{pH}$ 4. The initial $\mathrm{pH}$ for each flask was determined after the medium had been autoclaved but prior to inoculation. Experiments were repeated at least three times, and the results of a single representative experiment are shown. Differences between experiments in the average values for each treatment did not exceed 2 to $3 \%$.

\section{Fruit inoculation.}

Freshly harvested avocado cv. Fuerte fruits from an orchard at Kibbutz Givat Brenner (Israel) were used for inoculations. Spores of the various $C$. gloeosporioides strains were inoculated on the avocado fruit peel by placing $7 \mu \mathrm{l}$ of a conidial suspension $\left(10^{6}\right.$ conidia $\left.\mathrm{ml}^{-1}\right)$ on each of three longitudinally spaced inoculation spots on each side of each of 10 different fruits per treatment, i.e., 60 inoculation replicates per treatment. When fruits were inoculated on the mesocarp, a 1- to 2$\mathrm{mm}$ strip of peel tissue was removed from the fruit and $7 \mu \mathrm{l}$ of a conidial suspension $\left(10^{6}\right.$ conidia $\left.\mathrm{ml}^{-1}\right)$ was placed into $1-\mathrm{mm}$ deep, 1-mm diameter inoculation spots in the fruit mesocarp. Five inoculation spots, longitudinally spaced on each side of each of 10 different fruits were inoculated per treatment.

For detection of gene expression during assessment of avocado decay development, a bulk-inoculation method similar to that described by Alkan and associates (2008) was used. Briefly, 
5-day-old mycelium of C. gloeosporioides strains was cultured for 3 days in $\mathrm{M}_{3} \mathrm{~S}$ medium and was then washed twice with sterile water. The washed mycelia were inoculated into holes, 2 $\mathrm{mm}$ deep and $5 \mathrm{~mm}$ in diameter, pierced into the mesocarp. After inoculation, the fruits were incubated for $24 \mathrm{~h}$ at $22^{\circ} \mathrm{C}$ and $95 \%$ relative humidity in covered plastic containers containing wet paper towels and were then further incubated until symptoms were observed. In all experiments, the average decay diameters \pm standard deviation (SD) are reported. The inoculation experiments were repeated three times and one representative experiment is presented.

\section{Spore-germination and appressorium-induction assay.}

For RNA extraction and ammonia detection in germinating spores producing appressoria ('pathogenic' germination according to Barhoom and Sharon [2004]), conidia of C. gloeosporioides $\left(10^{6}\right.$ conidia per dish) were spread onto petri dishes (13-cm diameter) containing $10 \mathrm{ml}$ of water and were incubated for $12 \mathrm{~h}$. The germinated conidia producing appressoria were then harvested by scraping them off the petri dishes and centrifuging them at $10,000 \mathrm{rpm}$ for $15 \mathrm{~min}$. The pellet containing conidia and appressoria was harvested by filtering through filter paper, was lyophilized, and was subjected to RNA extraction. The supernatant was used for ammonia detection. For RNA extraction and ammonia detection in germinating spores not producing appressoria ('saprophytic' germination according to Barhoom and Sharon [2004]), conidia $\left(10^{6}\right.$ conidia per dish) were inoculated into a $125-\mathrm{ml}$ petri flask containing $10 \mathrm{ml}$ of $\mathrm{M}_{3} \mathrm{~S}$ broth medium, were incubated for $12 \mathrm{~h}$ with shaking (150 $\mathrm{rpm})$, and were harvested as described previously.

For appressorium formation and maturation-detection experiments, C. gloeosporioides WT and GDH2-disruption isolates were observed on glass slides. Briefly, 5 to $25 \mu$ l of a conidial suspension $\left(10^{6}\right.$ conidia per $\left.\mathrm{ml}\right)$ of each isolate was placed on five glass slides, which were kept on moistened filter paper in a moist chamber. After 12 to $14 \mathrm{~h}$ of incubation, conidial germination and appressorium development were observed in three microscopic fields in each of five cells per slide. Maturation of appressoria was defined according to the melanization level. Only appressoria that were fully melanized were considered mature compared with hyalineless pigmented ones, which were considered not mature. External ammonia was supplied as $\mathrm{NH}_{4} \mathrm{Cl}$ at $\mathrm{pH} 8.0$ in the humid chamber without contacting the spore suspension.

\section{pH measurement and ammonia detection.}

The $\mathrm{pH}$ was measured in $0.5-\mathrm{ml}$ aliquots taken at various times after fungal inoculation with a Thermo-Orion Model 9810BN microcombination $\mathrm{pH}$ electrode (Thermo Fisher Scientific, Inc., Waltham, MA, U.S.A.). Ammonia was detected colorimetrically with an ammonium test kit (Merck, Darmstadt, Germany). Samples $(0.5 \mathrm{ml})$ of the culture media were diluted with $4.5 \mathrm{ml}$ of double-distilled water, and the concentration of ammonia was determined according to the manufacturer's instructions. Briefly, the sample containing ammonium was adjusted to $\mathrm{pH} 13$, so that the ammonium was transformed to ammonia, which could then be detected colorimetrically at 690 $\mathrm{nm}$. Concentrations were reported as millimoles of ammonia.

For determination of ammonia accumulation and alkalinization inside the germinated spores, staining with the fluorescent dye BCECF (2',7'-bis(carboxyethyl)-5(6)-carboxyfluorescein) (Molecular Probes, Invitrogen, Leiden, The Netherlands) was used as described previously by Alkan and associates (2008).

\section{RNA extraction and cDNA library construction.}

Two cDNA libraries of $C$. gloeosporioides, representing in vitro and in vivo alkalinization processes, were constructed.
The in vitro library was constructed from hyphae of C. gloeosporioides during alkalinization of SM amended with avocado cell wall and L-glutamine. The in vivo library was constructed from hyphae of $C$. gloeosporioides growing on avocado fruit. For the construction of the in vitro library, the fungus was grown in $40 \mathrm{ml}$ of primary medium that had been inoculated with spores at a concentration of $1 \times 10^{6}$ spores per flask. The cultures were incubated at 22 to $24^{\circ} \mathrm{C}$ in a shaking incubator at $150 \mathrm{rpm}$ for 3 days and were harvested by filtration through filter paper in a sterile Büchner funnel. The collected hyphal mat was washed twice with $40 \mathrm{ml}$ of sterile distilled water. The washed mycelia were resuspended in $40 \mathrm{ml}$ of fresh medium containing $1 \%$ avocado cell wall as a carbon source and 50 $\mathrm{mM}$ L-glutamine as a nitrogen source. The medium was buffered with $50 \mathrm{mM}$ phthalate-hydroxide buffer to $\mathrm{pH}$ 6.0. After $24 \mathrm{~h}$ at 22 to $24^{\circ} \mathrm{C}$ in a shaking incubator at $150 \mathrm{rpm}$, the mycelia were collected, washed, and frozen, were dried by lyophilizer, and were stored at $-80^{\circ} \mathrm{C}$ pending use. The in vivo library was generated from fungus growing on avocado fruits. Freshly harvested Colletotrichum spores $\left(1 \times 10^{6}\right.$ spores $\left.\mathrm{ml}^{-1}\right)$ were placed on a $0.45-\mu \mathrm{m}$ nylon filter (Pall, Ann Arbor, MI, U.S.A.) mounted over a 3- to 4-cm diameter slice of avocado flesh at an initial $\mathrm{pH}$ of 5.7 and were stored at $25^{\circ} \mathrm{C}$ at high humidity under aseptic conditions. Three days later, when the fungus had developed a heavy mat on the nylon filter and had macerated the flesh to a depth of 3 to $4 \mathrm{~mm}$, the nylon filter was detached from the avocado tissue and the mycelia were collected and frozen under liquid nitrogen, were dried by lyophilizing, and were stored at $-80^{\circ} \mathrm{C}$ pending use.

Extraction of RNA for libraries, macroarray hybridization, and real-time qPCR analysis was extracted from $80 \mathrm{mg}$ (DW) of mycelium with an RNeasy plant minikit (Qiagen Sciences, Hilden, Germany) and was further purified by treatment with a TURBO DNA free kit (Ambion, Austin, TX, U.S.A.). Poly $(\mathrm{A})^{+}$RNA isolation was purified using the Dynabeads mRNA purification kit (Dynal Biotech, Oslo, Norway). cDNA was synthesized with the pBluescript II XR cDNA library construction kit (Stratagene Cloning Systems, La Jolla, CA, U.S.A.), which generates directional cDNA libraries. For construction of the libraries, the cDNA was size-fractionated with a gel-filtration column, and three fractions containing most of the cDNA were ligated into the plasmid vector and were subsequently packaged by means of the GigaPack III gold packaging extract kit (Stratagene).

\section{cDNA macroarray preparation, hybridization, and data analysis.}

The Uni-Zap XR vector enables efficient in vivo excision of single genes from the phagemid containing the clone insert to SOLAR bacteria (E. coli strain). SOLAR bacteria were plated on Luria-Bertani (LB)-ampicillin agar plates and were incubated overnight at $37^{\circ} \mathrm{C}$. Single colonies were then carefully transferred to 384-well freezing media broth plates containing (per liter): $25 \mathrm{~g} \mathrm{LB}$ powder, $6.2 \mathrm{~g} \mathrm{~K}_{2} \mathrm{HPO}_{4}, 1.8 \mathrm{~g} \mathrm{KH}_{2} \mathrm{PO}_{4}, 0.5$ $\mathrm{g} \mathrm{Na}_{3} \mathrm{C}_{6} \mathrm{H}_{5} \mathrm{O}_{7}, 0.9 \mathrm{~g}\left(\mathrm{NH}_{4}\right)_{2} \mathrm{SO}_{4}, 44 \mathrm{ml}$ glycerol, $400 \mu \mathrm{l}$ of $1 \mathrm{M}$ $\mathrm{MgSO}_{4} \cdot 7 \mathrm{H}_{2} \mathrm{O}$, and $100 \mu \mathrm{g} \mathrm{ml}^{-1}$ ampicillin. After $24 \mathrm{~h}$ at $37^{\circ} \mathrm{C}$ in a shaking incubator, the plates were collected and kept at $-80^{\circ} \mathrm{C}$, pending printing. A total of 26 plates containing around 9,984 single colonies were spotted on a Hybond membrane (Amersham, Piscataway, NJ, U.S.A.) by a Q-BOT robot (Genetix, Hampshire, U.K.). The printing was done by MRC Geneservice (Cambridge, U.K.). The spots were printed in duplicate, giving a total of 19,968 spots. The spots in the macroarray membrane were placed at $1.5-\mathrm{mm}$ resolution, and the membrane was cross-linked by UV irradiation $(3,600 \times$ $100 \mu \mathrm{J} \mathrm{cm}^{-2}$ ). For the hybridization experiments, $2 \mu \mathrm{g}$ of amplified mRNA, obtained using an Amino Allyl Message- 
Amp II aRNA amplification kit (Ambion), was prepared. cDNA was obtained by reverse transcription of mRNA by MMLV reverse transcriptase (Promega, Madison, WI, U.S.A.) and was labeled in the presence of Random Primer-Hexamer (Invitrogen, Carlsbad, CA, U.S.A.), dNTP and $\left[{ }^{33} \mathrm{P}\right]-\alpha-\mathrm{dCTP}$ (Amersham, Bucks, U.K.). Labeled cDNA was hybridized to the macroarray. The hybridization system was a standard saline phosphate system containing $10 \mathrm{ml}$ of $0.5 \mathrm{M}$ phosphate buffer, $\mathrm{pH} 7.2,1.0 \mathrm{mM}$ EDTA, 7\% (wt/vol) sodium dodecyl sulfate and $1 \%$ (wt/vol) bovine serum albumin. After $24 \mathrm{~h}$ of prehybridization, $24 \mathrm{~h}$ of hybridization, and three 20 -min washes in $2 \times \mathrm{SSC}(1 \times \mathrm{SSC}$ is $0.15 \mathrm{M} \mathrm{NaCl}$ plus $0.015 \mathrm{M}$ sodium citrate) at $25^{\circ} \mathrm{C}, 1 \times \mathrm{SSC}$ at $65^{\circ} \mathrm{C}$, and $0.1 \times \mathrm{SSC}$ at $65^{\circ} \mathrm{C}$, respectively, the membranes were exposed overnight to a phosphor-imager plate screen and were scanned with a Typhoon Scanner (Fuji, Tokyo) to detect hybridization signals. Files of the scanned images were analyzed with ArrayGauge software (Fuji). The intensity of each spot encodes information on a specific gene from the tested sample. For the macroarray data analysis, gene transcription was determined by using two independent biological replicates for each $\mathrm{pH}$ (two replicates per duplicate spot, i.e., four repetitions). The basal mean was determined as the median intensity of the signal around the spot region. Hybridization data from the text files were expressed as mean \pm SD between the two duplicates and were imported to a Microsoft Excel spreadsheet. Results of hybridization on the cDNA macroarray were normalized by global array signal for each experiment. A spot, whose expression values differed by a factor of 3 between treatments, supported by visual verification, was chosen and sequenced.

\section{Cloning of C. gloeosporioides MEPB and GDH2.}

The gene encoding $C$. gloeosporioides $M E P B$ was cloned by PCR using primers MEPB-CLO-F and MEPB-CLO-R (Table $5)$, which were designed on the basis of conserved sequences. C. gloeosporioides cDNA was subjected to PCR in a reaction volume of $50 \mu \mathrm{l}$ with $1 \mathrm{ng}$ of DNA, $50 \mathrm{pmol}$ of oligonucleotide primers, $25 \mu \mathrm{M}$ dNTPs, and $2.5 \mathrm{U}$ of Taq polymerase (MBI Fermentas, Vilnius, Lithuania) in $1 \times$ PCR buffer. For cloning of the PCR products, the reaction mix was separated on an agarose gel, and the fragment was purified with the Qiaex II gel extraction kit (Qiagen Sciences) and was cloned into the Tcloning vector of pGEM-T Easy (Promega). The $M E P B$ sequence of $C$. gloeosporioides showed the highest degree of identity at the amino-acid level to those of Neurospora crassa (84\%, XM_956584) and Aspergillus fumigatus (79\%, XM_747365) (Marini et al. 1997; Teichert et al. 2008).

The GDH2 EST was initially identified from macroarray experiments. We used the EST sequence and PCR to obtain a large genomic clone of $\mathrm{GDH} 2$ (GenBank accession number EU182718). The GDH2 sequence of $C$. gloeosporioides showed the highest degree of identity at the amino-acid level to $G D H 2$ genes from Gibberella fujikuori (84\%, AJ310444), Neurospora crassa (84\%, XM_951687), Aspergillus fumigatus (75\%, XM_74436), Neosurtorya fischeri (75\%, XM_001260221), and Magnaporthe grisea (80\%, XM_35 9530).

\section{Disruption and characterization \\ of the $C$. gloeosporioides $G D H 2$ gene.}

The gdh2 disruption construct, including the hygromycin marker gene and $G D H 2$ flanking sequences, was constructed using the following methodology. First, the modified primer pair $\mathrm{GDH} 2-5^{\prime} \mathrm{C}$ was used to PCR-amplify $666 \mathrm{bp}$ from the upstream region of the $G D H 2$ gene (position on $G D H 2$ sequence, 146 to 812) on Colletotrichum genomic DNA. The second PCR for the gdh2 3' region was performed on Colletotrichum genomic DNA by using the modified primer pair GDH2-3' (position on $G D H 2$ sequence, 910 to 1,463 ) (Table 5). The two PCR products were gel-purified using the Qiaquick kit (Qiagen Sciences) and were introduced into entry clones with the appropriate sites. In the next step, these two plasmids were assembled together with Hyg entry clone plasmid (Shafran et al. 2008), using the Multisite Gateway three-fragment vector construction kit (Invitrogen). Full details of this method are described elsewhere (Shafran et al. 2008). The NotI fragment was used to create the GDH2 knockout. Fungal transformation essentially followed that described in Yakoby and associates (2001). The $\Delta g d h 2$ disruption strains were obtained by a double-crossover event, exchanging the GDH2-coding region for the disruption cassette. A PCR screen of putative transformants for integration of the disruption cassette at the $G D H 2$ locus was employed with three sets of primers, GDH2 CON 5'F and GDH2 CON 3'R designed on the basis of the region flanking the disruption cassette at the $5^{\prime}$ and $3^{\prime}$ ends, respectively, and primer set HYG, as listed in Table 5. Southern probe labeling and Southern hybridization to confirm a single gene disruption event in $\Delta g d h 2_{640}, \Delta g d h 2_{689}$, and $\Delta g d h 2_{680}$ (Fig. 7B) were carried out according to the protocols described by Ausubel and associates (1991). For genomic DNA extraction, fungi were grown in liquid $\mathrm{M}_{3} \mathrm{~S}$ for 3 to 5 days at $28^{\circ} \mathrm{C}$. Genomic DNA $(10 \mu \mathrm{g})$ was digested with the restriction enzymes $B g l \mathrm{II}$ and BamHI. The probe was amplified by PCR from genomic DNA using primer pair GDH-P (Table 5).

\section{Semiquantitative and quantitative (q)PCR analysis.}

The reverse transcription reaction was performed on $10 \mu \mathrm{g}$ of total RNA with the Reverse-It first-strand synthesis kit (ABgene, Surrey, U.K.). Samples of cDNA were diluted 1:10 ( $\mathrm{vol} / \mathrm{vol})$ to the final template concentration for qPCR. The real-time qPCR was performed with the RotorGene 3000 system (Corbett Research, Sydney, Australia). PCR amplification was applied to $3.5 \mu \mathrm{l}$ of cDNA template in $10 \mu \mathrm{l}$ of a reaction mixture containing $5 \mu \mathrm{l}$ Syber-green amplification kit (ABgene) and $300 \mathrm{nM}$ of primers. PCR conditions were initial denaturation for $15 \mathrm{~min}$ at $94^{\circ} \mathrm{C}, 40$ denaturation cycles of $10 \mathrm{~s}$ at $94^{\circ} \mathrm{C}$, annealing at $60^{\circ} \mathrm{C}$ for $15 \mathrm{~s}$, extension at $72^{\circ} \mathrm{C}$ for $20 \mathrm{~s}$ (cycle A), at $77^{\circ} \mathrm{C}$ for $6 \mathrm{~s}$ (cycle B), and at $80^{\circ} \mathrm{C}$ for $6 \mathrm{~s}$ (cycle $\mathrm{C}$ ), and melting at 72 to $99^{\circ} \mathrm{C}$. For semiquantitative PCR, the products were resolved on $1.8 \%$ agarose gels. For qPCR, the samples were subjected to melting curve analysis with the RotorGene program. All samples were normalized to $18 \mathrm{~S}$ rRNA gene levels in the same qPCR, and the values were expressed as the increase or decrease of the levels relative to a calibration sample. The forward and reverse primers for all of the genes are summarized in Table 5. The experiment was repeated at least three times with similar results; the results of one experiment are presented.

\section{ACKNOWLEDGMENTS}

This work was supported by the U.S.-Israel Binational Agricultural Research and Development Fund. We thank S. Brown Horowitz, E. Or, and $\mathrm{H}$. Volpin for technical support. I. Miyara is grateful for a personal grant from ISEF organization.

\section{LITERATURE CITED}

Alkan, N., Fluhr, R., Sherman, A., and Prusky, D. 2008. Role of ammonia secretion and $\mathrm{pH}$ modulation on pathogenicity of Colletotrichum coccodes on tomato fruit. Mol. Plant-Microbe Interact. 21:1058-1066.

Alkan, N., Davydov, O., Sagi, M., Fluhr, R., and Prusky, D. 2009. Ammonium secretion by Colletotrichum coccodes activates host NADPH oxidase activity enhancing host cell death and fungal virulence in tomato fruits. Mol. Plant-Microbe Interact. 22:1484-1491.

Ausubel, F. M., Brent, R., Kingston, R. E., Moore, D. D., Seidman, J. G., Smith, J. A., and Struhl, K. 1991. Current Protocols in Molecular Biology. John Wiley and Sons, NewYork. 
Barhoom, S., and Sharon, A. 2004. cAMP regulation of pathogenic and saprophytic fungal spore germination. Fungal Genet. Biol. 41:317-326.

Caddick, M. X., Brownlee, A. G., and Arst, H. N. J. 1986. Regulation of gene expression by $\mathrm{pH}$ of the growth medium in Aspergillus nidulans. Mol. Gen. Genet. 203:346-353.

Diéguez-Uribeondo, J., Förster, H., and Adaskaveg. J. E. 2008. Visualization of localized pathogen-induced $\mathrm{pH}$ modulation in almond tissues infected by Colletotrichum acutatum using confocal scanning laser microscopy. Phytopathology 98:1171-1178.

Drori, N., Kramer-Haimovich, H., Rollins, J., Dinoor, A., Okon, Y., Pines, O., and Prusky, D. 2003. A combination of external pH and nitrogen assimilation affects secretion of the virulence factor pectate lyase by Colletotrichum gloeosporioides. Appl. Environ. Microbiol. 69:3258-3262.

Eshel, D., Miyara, I., Ailing, T., Dinoor, A., and Prusky, D. 2002. pH regulates endopolyglucanase expression and virulence of Alternaria alternata in persimmon fruit. Mol. Plant-Microbe Interact. 15:774-779.

Hao, R., and Schmit, J. C. 1991. Purifcation and characterisation of glutamate-decarboxylase from Neurospora crassa conidia. J. Biol. Chem. 266:5135-5139.

Hess, D. C., Lu, W., Rabinowitz, J. D., and Botstein, D. 2006. Ammonium toxicity and potassium limitation in yeast. PLoS Biol. 4:2012-2023.

Horowitz, S., Freeman, S., Zveibil, A., and Yarden, O. 2006. A defect in nir1, a nirA-like transcription factor, confers morphological abnormalities and loss of pathogenicity in Colletotrichum acutatum. Mol. Plant Pathol. 7:341-354.

Horowitz-Brown, S., Yarden, O., Gollop, N., Chen, S., Zveibil, A., Belausov, E., and Freeman, S. 2008. Differential protein expression in Colletotrichum acutatum: Changes associated with reactive oxygen species and nitrogen starvation implicated in pathogenicity on strawberry. Mol. Plant Pathol. 9:171-190.

Hwang, C. S., and Kolattukudy, P. E. 1995. Isolation and characterization of genes expressed uniquely during appressorium formation by Colletotrichum gloeosporioides conidia induced by the host surface wax. Mol. Gen. Genet. 247:282-294.

Jung, U. S., and Levin, D. E. 1999. Genome-wide analysis of gene expression regulated by the yeast cell wall integrity signaling pathway. Mol. Microbiol. 34:1049-1057.

Kramer-Haimovich, H., Servi, E., Katan, T., Rollins, J., Okon, Y., and Prusky, D. 2006. Effect of ammonia production by Colletotrichum gloeosporioides on pelB activation, pectate lyase secretion, and fruit pathogenicity. Appl. Environ. Microbiol. 72:1034-1039.

Marini, A. M., Soussi-Boudekou, S., Vissers, S., and Andre, B. 1997. A family of ammonium transporters in Saccharomyces cerevisiae. Mol. Cell. Biol. 17:4282-4293.

Miyara, I., Shafran, H., Kramer-Haimovich, H., Rollins, J., Sherman, A., and Prusky, D. 2008. Multifactor regulation of pectate lyase secretion by Colletotrichum gloeosporioides pathogenic on avocado fruits. Mol. Plant Pathol. 9:281-291.

Monahan, B. J., Askin, M. C., Hynes, M. J., and Davis, M. A. 2006. Differential expression of Aspergillus nidulans ammonium permease genes is regulated by GATA transcription factor AreA. Eukaryot. Cell 5:226-227.

Nesher, I., Barhoom, S., and Sharon, A. 2008. Cell cycle and cell death are not necessary for appressorium formation and plant infection in the fungal plant pathogen Colletotrichum gloeosporioides. BMC Biol. 14:6-9.

Oh, Y. Y., Donofrio, N., Pan, H., Coughlan, S., Brown, D. E., Meng, S. Mitchell, T., and Dean, R. A. 2008. Transcriptome analysis reveals new insight into appressorium formation and function in the rice blast fungus Magnaporthe oryzae. Genome Biol. 9:R85.

Pageau, K., Reisdort-Cren, M., Morot-Gaudry, J.-F., and MasclauxDaubresse, C. 2006. The two senescence-related markers, GS1 (cytosolic glutamine synthetase) and GDH (glutamate dehydrogenase), involved in nitrogen mobilization, are differentially regulated during pathogen attack and by stress hormones and reactive oxygen species in Nicotiana tabacum L. leaves. J. Exp. Bot. 57:547-557.

Palkova, Z., Devaux, F., Ricicova, M., Minarikova, L., Le Crom, S., and Jacq, C. 2002. Ammonia pulses and metabolic oscillations guide yeast colony development. Mol. Biol. Cell. 13:3901-3914.

Penalva, M. A., Tilburn, J., Bignell, E., and Arst, H. N., Jr. 2008. Ambient $\mathrm{pH}$ gene regulation in fungi: Making connections. Trends Microbiol. 16:291-300.

Plaine, A., Walker, L., Da Costa, G., Mora-Montes, H. M., McKinnon, A., Gow, N. A. R., Gaillardin, C., Munro, C. A.,, and Richard, M. L. 2008.
Functional analysis of Candida albicans GPI-anchored proteins: Roles in cell wall integrity and caspofungin sensitivity. Fungal Genet. Biol. 45:1404-1414.

Prusky, D. 1996 Pathogen quiescence in postharvest diseases. Annu. Rev. Phytopathol. 34:413-434.

Prusky, D., and Yakoby, N. 2003. Pathogenic fungi: Leading or led by ambient pH? Mol. Plant Pathol. 4:509-516.

Prusky, D., McEvoy, L., Leverentz, B., and Conway, W. S. 2001. Local modulation of host $\mathrm{pH}$ by Colletotrichum species as a mechanism to increase virulence. Mol. Plant-Microbe Interact. 14:1105-1113.

Ricicova, M., Kucerova, H., Vachova, L., and Palkova, Z. 2007. Association of putative ammonium exporters Ato with detergent-resistant compartments of plasma membrane during yeast colony development: $\mathrm{pH}$ affects Ato1p localization in patches. BBA-Biomembranes 1768:1170 1178

Schmit, J. C., and Brody, S. 1975. Neurospora crassa conidial germination: Role of endogenous amino acid pools. J. Bacteriol 124:232-242.

Schumacher, J., Viaud, M., Simon, A., and Tudzynski, B. 2008. The G alpha subunit $B C G 1$, the phospholipase $\mathrm{C}$ (BcPLC1) and the calcineurin phosphatase co-ordinately regulate gene expression in the grey mould fungus Botrytis cinerea. Mol. Microbiol. 67:1027-1050.

Shafran, H., Miyara, I., Eshed, R., Prusky, D., and Sherman, A. 2008. Development of new tools for studying gene function in fungi based on the Gateway system. Fungal Genet. Biol. 45:1147-1154.

Solomon, P. S., Tan, K. C., and Oliver, R. P. 2003. The nutrient supply of pathogenic fungi; a fertile field of study. Mol. Plant Pathol. 4:203-210.

Spreghini, E., Davis, D. A., Subaran, R., Kim, M., and Mitchell, A. P. 2003. Roles of Candida albicans D fg5p and Dcw1p cell surface proteins in growth and hypha formation. Eukaryot. Cell 2:746-755.

Stephenson, S. A., Green, J. R., Manners J. M., and Maclean, D. J. 1997. Cloning and characterization of glutamine synthetase gene from Colletotrichum gloeosporioides and demonstration of elevated expression during pathogenesis on Stylosanthes guianensis. Curr. Genet. 31:447454.

Talbot, N. J., Ebbole, D. J., and Hamer, J. E. 1993. Identification and characterization of MPG1, a gene involved in pathogenicity from the rice blast fungus Magnaporthe grisea. Plant Cell 5:1575-1590.

Tavernier, V., Cadiou, S., Pageau, K., Lauge, L., Reisdorf-Cren, M., Langin, T., and Masclaux-Daubresse, C. 2007. The plant nitrogen mobilization promoted by Colletotrichum lindemuthianum in Phaseolus leaves depends on fungus pathogenicity. J. Exp. Bot. 58:3351-3360.

Teichert, S., Schönig, B., Richter, S., and Tudzynski, B. 2004. Deletion of the Gibberella fujikuroi glutamine synthetase gene has significant impact on transcriptional control of primary and secondary metabolism. Mol. Microbiol. 53:1661-1675.

Teichert, S., Rutherford, J. C., Wottawa, M., Heitman, J., and Tudzynski, B. 2008. Impact of ammonium permeases MepA, MepB, and MepC on nitrogen-regulated secondary metabolism in Fusarium fujikuroi. Eukaryot. Cell 2:187-201.

Tu, J. C. 1985. An improved Mathur's medium for growth, sporulation and germination of spores of Colletotrichum lindemuthianum. Microbiosis 44:87-93.

Tucker, S. L., Thornton, C. R., Tasker, K., Jacob, C., Giles, G., Egan, M., and Talbot, N. J. 2004. A fungal metallothionein is required for pathogenicity of Magnaporthe grisea. Plant Cell 16:1575-1588.

Viladevall, L., Serrano, R., Ruiz, A., Domenech, G., Giraldo, J., Barcelo, A., and Ariño, J. 2004. Characterization of the calcium-mediated response to alkaline stress in Saccharomyces cerevisiae. J. Biol. Chem. 279:43614-43624.

Wattad, C., Freeman, S., Dinoor, A., and Prusky, D. 1995. A non-pathogenic mutant of Colletotrichum magnais deficient in extracellular secretion of pectate lyase. Mol. Plant-Microbe Interact. 4:621-626.

Yakoby, N., Kobiler, I., Dinoor, A., and Prusky, D. 2000. pH regulation of pectate lyase secretion modulates the attack of Colletotrichum gloeosporioides on avocado fruits. Appl. Environ. Microbiol. 66:1026-1030.

Yakoby, N., Beno-Moualem, D., Keen, N. T., Dinoor, A., Pines, O., and Prusky, D. 2001. Colletotrichum gloeosporioides pelB is an important virulence factor in avocado fruit-fungus interaction. Mol. Plant-Microbe Interact. 14:988-995.

Zikanova, B., Kuthan, M., Ricicova, M., Forstova, J., and Palkova, Z. 2002. Amino acids control ammonia pulses in yeast colonies. Biochem. Biophys. Res. Commun. 294:962-967. 